\title{
Would RC wide-beam buildings in Spain have survived Lorca earthquake (11- 05-2011)?
}

\author{
D. Domínguez ${ }^{1}$, F. López-Almansa ${ }^{2}$, A. Benavent-Climent ${ }^{3}$ \\ ${ }^{1}$ University of Talca, Faculty of Engineering, Department of Construction Engineering and Management, \\ Talca, Chile \\ ${ }^{2}$ Technical University of Catalonia, Architecture Structures Department, Barcelona, Spain \\ ${ }^{3}$ Technical University of Madrid, Mechanical Engineering Department, Madrid, Spain
}

Correspondence to: Francisco López-Almansa; Departament d'Estructures; ETSAB (UPC); Avda. Diagonal 649; 08028 Barcelona (Spain); Phone +34934016316, FAX +34934016096; E-mail: francesc.lopezalmansa@upc.edu

\begin{abstract}
Lorca earthquake (11-05-2011) is most destructive event recorded in Spain, causing nine fatalities and other severe consequences. Its important intensity was rather unexpected, and serious concern arose regarding risk of building stock in Spain. This paper analyzes performance, under Lorca earthquake, of RC buildings with one-way slabs with wide beams. This construction type is chosen for its high vulnerability and for being vastly widespread in Spain. This study is conducted on 3 and 6-story prototype representative buildings. These buildings are designed for three major seismic zones in Spain: low seismicity, moderate seismicity (as Lorca) and medium seismicity (as Granada). Seismic performance under Lorca earthquake is numerically investigated through nonlinear time-history analyses. Results show that buildings designed without any seismic provision (i.e. those in low seismicity zones) do not survive Lorca record, even with cooperation of masonry infill walls. Buildings with seismic design (i.e. those in Lorca and Granada zones) can survive Lorca earthquake only with collaboration of infill walls. To raise reliability of these conclusions, a sensitivity analysis to most influencing parameters is conducted.
\end{abstract}

Keywords: Collapse, Lorca earthquake, seismic vulnerability, time history, wide beams.

\section{Introduction}

In Spain, there are several common building types that are vulnerable to earthquakes, even in most seismic-prone regions. This situation can be attributed to a number of reasons: unawareness of actual seismic hazard, lenient prescriptions of design codes, and, in some occasions, lack of fulfillment of regulations and poor construction practices. Lorca earthquake (11-05-2011, $M_{\mathrm{w}}=5.1$ ) stressed gravity of situation, given that its high intensity was rather unexpected and many buildings were seriously damaged. Additionally, recent Ossa de Montiel earthquake (23-02-2015, $\left.M_{\mathrm{w}}=5.2\right)$ [IGME 2015] occurred in a supposedly non-seismic location; this event has confirmed that virtually any point in Spain can be struck by shakings with similar magnitude than Lorca earthquake, corresponding to return periods higher than expected. Given that these earthquakes have shown PGA associated with return periods higher than 500 years, it is worth investigating the realistic degree of safety of buildings in Spain.

This work is part of a wider long-term research effort aiming to mitigate seismic vulnerability of widespread buildings in Spain. Overall approach consists of identifying vulnerable construction typologies, evaluating their seismic risk and proposing retrofit strategies, mainly using energy dissipators. Inside this long-term research, two major types of RC buildings are considered so far: two-way waffle slabs and one-way wide-beam slabs. Regarding abovementioned long-term research on wide-beam buildings, earlier works consisted of experiments aiming to characterize hysteretic behavior of wide beam-column joints [Benavent-Climent 2007; Benavent-Climent et al. 2009a,b] providing drift ratio at first yielding and at failure $2.45 \%$ and $4.5 \%$, respectively; 
displacement ductility was 2.5. Such tests took profit of previous studies by other researchers [Popov et al. 1992; Gentry, Wight 1994; Quintero-Febres, Wight 2001; Siah et al. 2003]; these studies proposed detailing strategies and concluded that beam width must not exceed bc +2 hc (bc and hc are base and depth of column) to ensure a satisfactory seismic performance. Posterior studies investigated numerically vulnerability of code-compliant buildings [Benavent-Climent, Zahran 2010] and of non-code-compliant buildings [Domínguez 2012; López-Almansa et al. 2013]; first study proposed a methodology for assessing seismic capacity of existing frames in terms of energy while second study pointed out low seismic capacity of analyzed buildings and need of considering cooperation of nonstructural walls. More recent works discuss behavior, under Lorca input, of buildings located in Lorca [Benavent-Climent et al. 2013] and of non-code compliant buildings located in any zone of Spain [Domínguez et al. 2014], respectively; first study concluded that pilotis configuration makes structure prone to damage concentration and reduces its seismic capacity, while second study showed that all analyzed buildings would not have survived Lorca earthquake. This work is an extension of two aforementioned studies [Benavent-Climent et al. 2013; Domínguez et al. 2014] to any type of wide-beam buildings located in any region of Spain. Next stage of research will consist in proposing retrofit solutions for these buildings; this activity is currently in progress.

Research approach of this paper consists in selecting a number of prototype buildings and investigating numerically their performance under Lorca earthquake. Thus, two buildings, 3 and 6story, are chosen to represent vast majority of edifices with wide beams located in Spain. Each building is designed for three major seismic zones in Spain: low seismicity, moderate seismicity (as Lorca) and medium seismicity (as Granada). Finite element models accounting for cooperation of masonry infill walls to lateral strength describe structural behavior of prototype buildings; for each building, three wall densities are considered: no walls, low wall density and high wall density. Overall seismic resistance of prototype buildings is firstly assessed by pushover analysis; then, their performance under Lorca earthquake is evaluated from dynamic responses under its most severe records. Thus, maximum displacements obtained from time-history analyses are compared with capacity of buildings determined from pushover analyses. Since most damage caused by Lorca earthquake was generated by debris fall, absolute accelerations are also determined. Given that actual buildings are not uniform, sensitivity of obtained results to major building parameters is investigated.

This paper shows convincingly that an important number of buildings in Spain would have collapsed under an earthquake that actually occurred. This announcement can raise public awareness of seismic risk in Spain. Moreover, proposing feasible solutions to this problem, can persuade Spanish officials to undertake retrofit campaigns.

\section{Wide-beam buildings in Spain}

\subsection{Description of wide-beam buildings}

Wide-beam buildings have a concrete framed structure with one-way slabs. Beams are as deep as slabs, thus providing flat soffit, which facilitates construction of slabs and layout of facilities. Figure 1 displays an image and a sketch of one-way slabs with wide beams. 


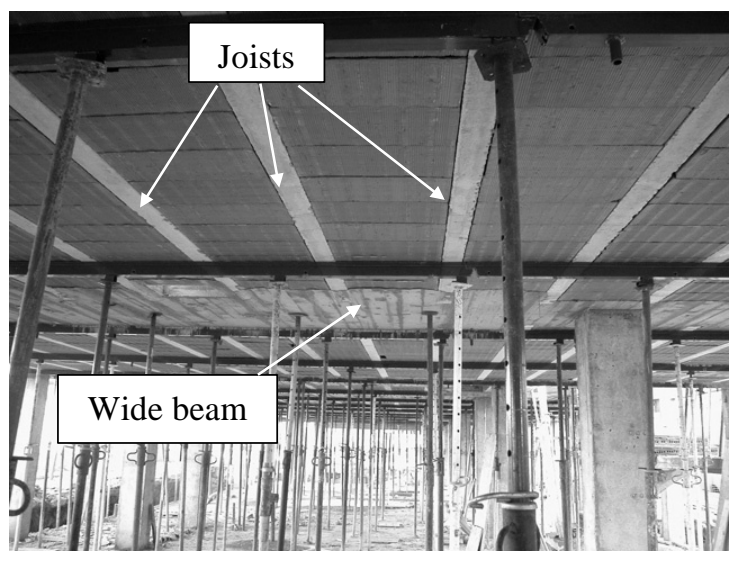

(a) Lower view of a one-way slab with wide beams

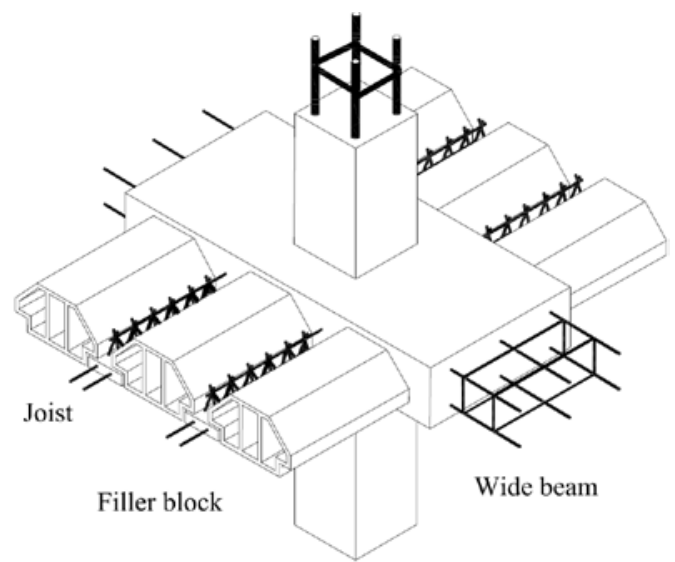

(b) Wide beam-column connection

Figure 1. Wide-beam slabs

Wide-beam buildings are potentially highly vulnerable to earthquakes. In wide beams direction, following weaknesses can be presumed:

- Low lateral strength and stiffness, because effective depth of beams is small (compared to conventional beams).

- Low ductility, in terms of chord rotation, since total reinforcement amount of wide beams is high (commonly ranging between $2 \%$ and $6 \%$ ) to compensate for insufficient effective depth.

- Considerable strut compressive forces developed inside column-beam joints, due to low height of wide beams. This weaknesses correspond mainly to non code-compliant buildings, since Spanish design code [NCSE-02] requires strut verification.

- Beams depth is smaller than their width, therefore, usually beams are wider than columns, and part of their longitudinal reinforcement lies outside columns projection (Figure 1.b). Hence, contribution of outer zones of beams to bending resistance of connections involves torsion mechanisms. However, resistance of strut-and-tie mechanisms cannot be guaranteed, since reinforcement is not designed for this purpose in common Spanish practice.

In orthogonal direction, lateral seismic behavior might be even worse, since the only members of slabs that contribute to lateral resistance of buildings are joists and façade beams [Domínguez 2012; López-Almansa et al. 2013].

\subsection{Prototype buildings}

Two prototype buildings are chosen to represent vast majority of wide-beam edifices in Spain. Characteristics of both prototypes are determined from an extensive survey among experienced designers [Domínguez 2012]. These two buildings have 3 and 6-stories, respectively; first floor is 4 $\mathrm{m}$ high while upper floors are $3 \mathrm{~m}$ high. Influence of basements is neglected. Each building has fours bays in both directions; columns are regularly distributed and span-length is $5 \mathrm{~m}$ in both directions. All buildings are regular, having plan symmetry and uniformity along height, with uninterrupted columns (continuous down to foundation). Noticeably, in Spain there are only few actual asymmetric wide-beam buildings; moreover, do not follow well-defined common patterns. Hence, this study considers only symmetric buildings. 


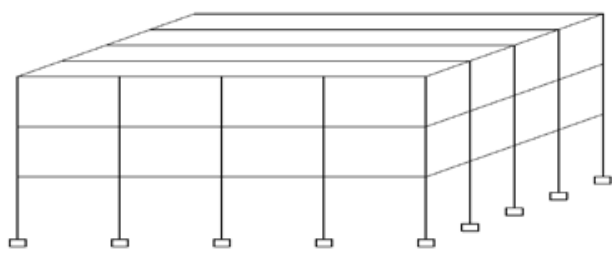

(a) 3-story building
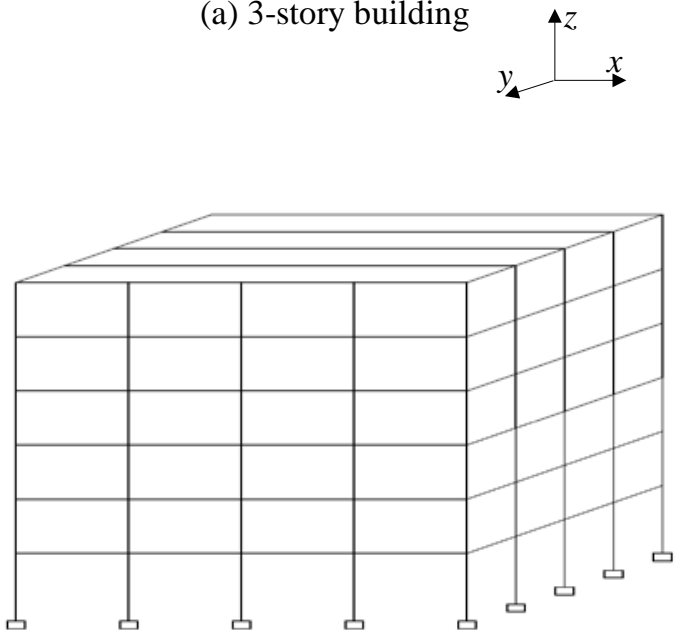

(c) 6-story building

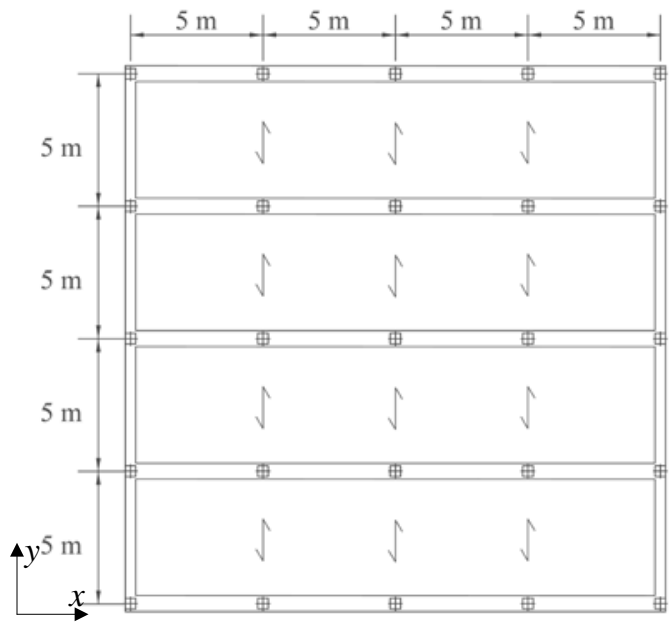

(e) Plan floor

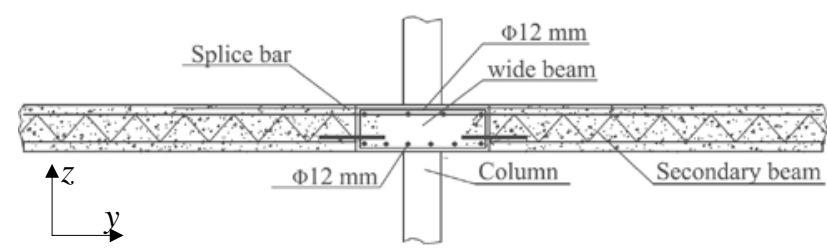

(b) Column-wide beam connection (non code-compliant building)

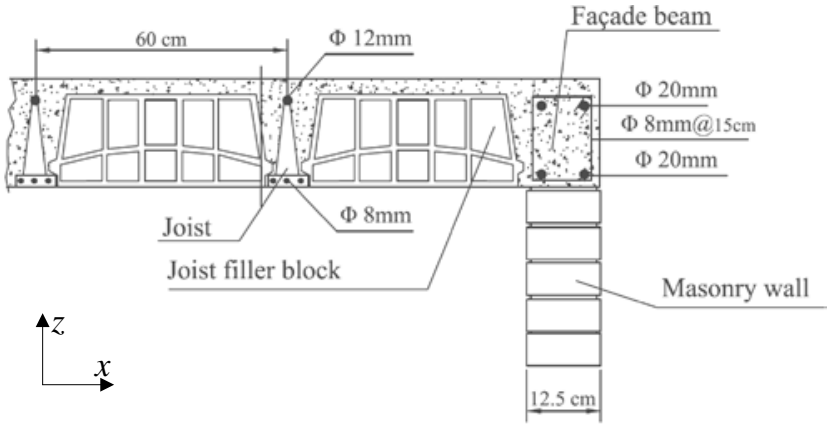

(d) Column-façade beam connection (non code-compliant building)

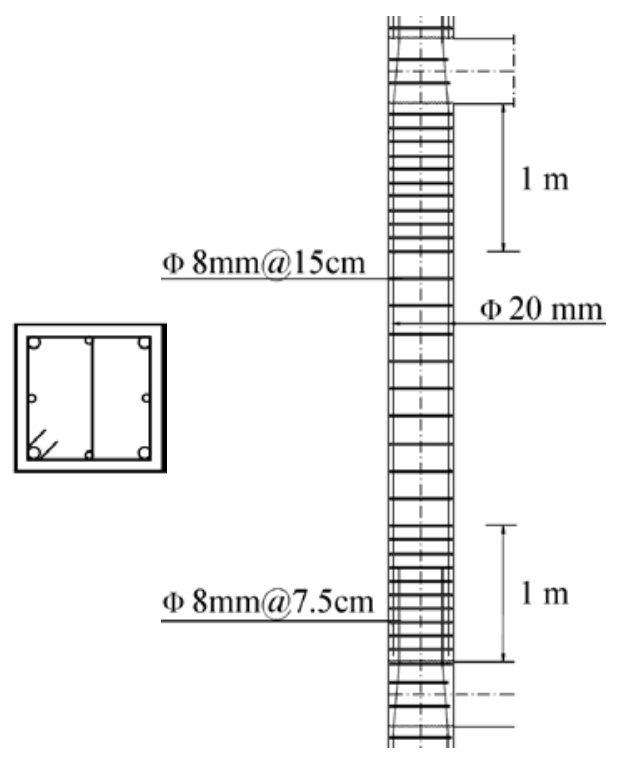

(f) Column elevation and section

Figure 2. Prototype buildings

Figure 2 displays several views and details of prototype buildings. Figure 2.a and Figure 2.c contain overall views of 3-story and 6-story buildings, respectively. Figure 2.e displays a plan view of a slab; that sketch highlights that in $x$ direction every slab contains five wide beams while in $y$ direction there are two (outer) façade beams and three (inner) joists that are coplanar with columns. Figure 2.b and Figure 2.d display cross-sections on $y$ and $x$ directions, respectively; those sketches show wide beams wider than columns, whereas façade beams are as wide as columns. Two types of joists are typically employed: (i) semi-prefabricated beams, being composed of a lower "sole" and a "truss-type" bare reinforcement (Figure 2.b and Figure 2.d), and (ii) prefabricated prestressed 
beams. Figure 2.b shows that top splice bars guarantee joists continuity. Figure 2.f displays an elevation and a cross section of a column. Figure 2.f shows that lap splices are concentrated in bottom sections, in contrast to common recommendations. Transverse reinforcement in wide beams consists of single stirrups made of $6-8 \mathrm{~mm}$ diameter bars and spaced $15 \mathrm{~cm}$. Transverse reinforcement in columns consists of single stirrups made of 6-8 $\mathrm{mm}$ diameter bars; in end segments (1 m long each) spacing is $7.5 \mathrm{~cm}$, and in center segments (1 m long each) is $15 \mathrm{~cm}$ (Figure 2.f). Noticeably, both in columns and beams, hook on stirrups or hoops have a bend of $90^{\circ}$, instead of $135^{\circ}$. In façade beams, longitudinal reinforcement is described in Figure 2.d and transverse reinforcement consists of single stirrups made of 6-8 mm diameter bars and spaced 15 $\mathrm{cm}$.

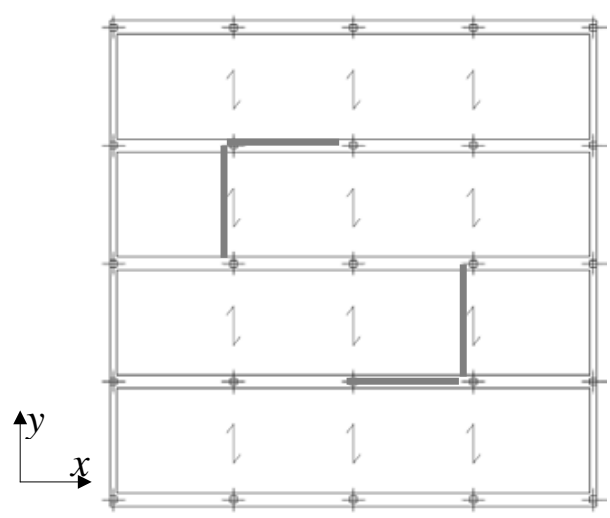

(a) Low wall density

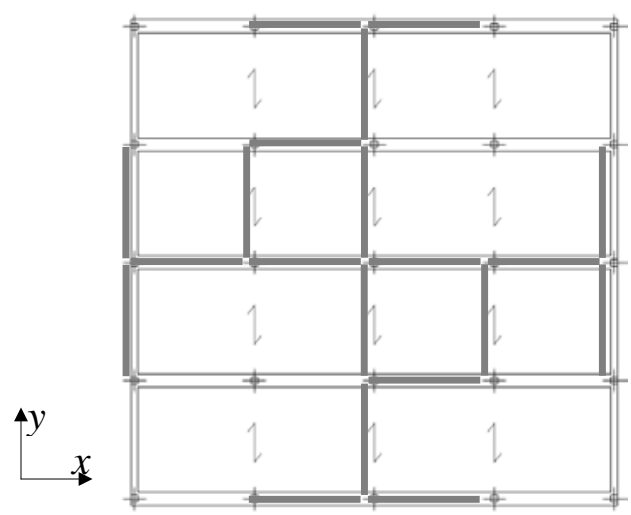

(b) High wall density

Figure 3. Infill walls layout

Given that lateral resistance of prototype buildings is low, cooperation of nonstructural infill walls must be taken into consideration. Work [Ricci et al. 2013] discusses profoundly this issue. In this paper, for each prototype building three wall densities are considered: no walls, low wall density and high wall density. First and second cases correspond to commercial buildings with light claddings, while third case corresponds to houses. Figure 3 depicts typical layouts of walls for second and third cases. Only wall panels without openings are considered. Since in Figure 3 infill walls are laid symmetrically in both directions, plan symmetry holds. All walls are continuous down to foundation; although pilotis (e.g. lack of walls in first floor) are extremely prejudicial [Ricci et al. 2013; Benavent-Climent et al. 2012, 2013], is not contemplated in this study because this has been analyzed in a previous work [Benavent-Climent et al. 2013]. On each level, walls extend to full height; therefore, short column effects are not taken into consideration. Walls are unreinforced and are stabbed to adjoining columns, without steel ties. Only contribution of walls made with Group 2 brick units [EN 1996 2005] that are $12 \mathrm{~cm}$ thick is accounted for. Cooperation of walls made with Group 3 or Group 4 brick units [EN 1996 2005] is neglected, given their brittle behavior [Martínez et al. 2001]. Characteristic values of brick and mortar strengths are 12 and $8 \mathrm{MPa}$, respectively.

Each prototype building is designed for low, moderate and medium seismicity. Seismicity is established in terms of design Peak Ground Acceleration (PGA) according to Spanish regulations [NCSE-02 2002]: low PGA < $0.08 \mathrm{~g}$, moderate $0.08 \mathrm{~g} \leq \mathrm{PGA}<0.16 \mathrm{~g}$, and medium $0.16 \mathrm{~g} \leq \mathrm{PGA}$. Low seismicity buildings are designed without any seismic provision (PGA $=0.0 \mathrm{~g}$ ) and are termed thereafter non-code-compliant buildings. Buildings for moderate and medium seismicity regions are located in Lorca (PGA $=0.12 \mathrm{~g}$ ) and Granada (PGA $=0.23 \mathrm{~g}$ ), respectively. Differentiating characteristics of prototype buildings without and with seismic design are described next. 
Non code-compliant buildings. Characteristic value of concrete compressive strength is $f_{\mathrm{ck}}=17.5$ $\mathrm{MPa}$; top concrete layer of slabs is unreinforced and is $4 \mathrm{~cm}$ deep (Figure 2.d and Figure 2.e). Steel type is AEH $400 \mathrm{~S}$ [EH-80 1980]; yield point and ultimate stress and strain are $f_{\mathrm{yk}}=410 \mathrm{MPa}, f_{\mathrm{u}}=$ $530 \mathrm{MPa}$, and $\varepsilon_{\mathrm{u}}=14 \%$, respectively.

Code-compliant buildings. Prototype buildings in moderate and medium seismicity regions are designed according to current Spanish [NCSE-02 2002] code. However, since major objective of this paper is to asses actual buildings, recommendations of NCSE-02 that are commonly ignored by designers, are also disregarded. Design is based on static equivalent forces in both horizontal directions. Static forces are obtained from response spectra for $5 \%$ damping. Aforementioned design accelerations $(0.12 \mathrm{~g}$ and $0.23 \mathrm{~g})$ correspond to stiff soil ( $360<v_{\mathrm{s}, 30}<800 \mathrm{~m} / \mathrm{s}$, where $v_{\mathrm{s}, 30}$ is shear wave velocity averaged over top $30 \mathrm{~m}$ ) and 500 year return period. Initially, for each building, four major soil types included in European regulations [EN 1998 2004] are considered: A (rock, $v_{\mathrm{s}, 30}>800 \mathrm{~m} / \mathrm{s}$ ), B (stiff soil, $360<v_{\mathrm{s}, 30}<800 \mathrm{~m} / \mathrm{s}$ ), C (soft soil, $180<v_{\mathrm{s}, 30}<360 \mathrm{~m} / \mathrm{s}$ ) and D (very soft soil, $v_{\mathrm{s}, 30}<180 \mathrm{~m} / \mathrm{s}$ ). However, it is found that wide-beam buildings are not feasible in soils B, $\mathrm{C}$ and $\mathrm{D}$ because design would require excessive slabs depth and too massive columns; therefore, finally only soil A is considered. For soil A, beams cannot be as wide as in non-code-compliant buildings because of code limitations in percentage of top longitudinal reinforcement of beams that lie out of column projection. Response reduction factor is 2, and no accidental eccentricity is considered. Seismic structural design is done emulating common practices in Spain; accordingly, cooperation of masonry infill walls is not taken into consideration. Characteristic value of concrete compressive strength is $f_{\mathrm{ck}}=25 \mathrm{MPa}$; top concrete layer of slabs is reinforced $(15 \times 15 \mathrm{~cm}$ wire mesh made with $5 \mathrm{~mm}$ diameter bars) and is $5 \mathrm{~cm}$ deep. Steel type is B 500 SD [EHE 2008] (high ductility); yield point and ultimate stress and strain are $f_{\mathrm{yk}}=500 \mathrm{MPa}, f_{\mathrm{u}}=575 \mathrm{MPa}$, and $\varepsilon_{\mathrm{u}}=16 \%$, respectively. Given abovementioned lack of fulfillment of some code recommendations, hierarchy of resistance between columns and beams is not considered. As well, regarding joists, are designed only for gravity loads and bottom reinforcement bars are not adequately anchored. Noticeably, NCSE-02 advises that joists are designed as main beams, although this suggestion is not widely fulfilled.

Table 1 describes main characteristics of prototype buildings. In notation "B3-0.0g", 3 refers to number of floors and $0.0 \mathrm{~g}$ corresponds to PGA. Weight corresponds to loading combination $G+0.3$ $Q ; G$ and $Q$ represent dead and live loads, respectively. Fundamental periods are determined with numerical models described in section 3. Left / right figures correspond, respectively, to $x$ / $y$ directions (Figure 3).

Table 1. Prototype buildings

\begin{tabular}{|c|c|c|c|c|c|c|c|c|}
\hline \multirow[b]{2}{*}{ Building } & \multirow{2}{*}{$\begin{array}{c}\text { Building } \\
\text { height } \\
\text { (m) }\end{array}$} & \multirow{2}{*}{$\begin{array}{c}\text { First } \\
\text { floor } \\
\text { columns } \\
(\mathbf{c m})\end{array}$} & \multirow{2}{*}{$\begin{array}{c}\text { Top } \\
\text { floor } \\
\text { columns } \\
(\mathbf{c m}) \\
\end{array}$} & \multirow{2}{*}{$\begin{array}{c}\begin{array}{c}\text { Wide } \\
\text { beams }\end{array} \\
(b \times h) \\
(\mathrm{cm})\end{array}$} & \multirow{2}{*}{$\begin{array}{c}\text { Seismic } \\
\text { weight } \\
(G+0.3 \\
Q)(\mathrm{kN})\end{array}$} & \multicolumn{3}{|c|}{ Fundamental periods $(x / y)(s)$} \\
\hline & & & & & & No walls & $\begin{array}{l}\text { Low wall } \\
\text { density }\end{array}$ & $\begin{array}{l}\text { High wall } \\
\text { density }\end{array}$ \\
\hline B3-0.0g & 10 & $40 \times 40$ & $30 \times 30$ & $60 \times 25$ & 9770 & 0.585 / 1.037 & 0.264 / 0.285 & $0.126 / 0.128$ \\
\hline B3-0.12g & 10 & $40 \times 40$ & $30 \times 30$ & $50 \times 35$ & 10935 & $0.407 / 0.524$ & $0.119 / 0.125$ & $0.118 / 0.125$ \\
\hline B3-0.23g & 10 & $50 \times 50$ & $40 \times 40$ & $60 \times 40$ & 12005 & $0.241 / 0.302$ & $0.117 / 0.119$ & $0.110 / 0.114$ \\
\hline B6-0.0g & 19 & $50 \times 50$ & $30 \times 30$ & $60 \times 25$ & 20310 & $1.333 / 2.630$ & $0.400 / 0.413$ & $0.185 / 0.187$ \\
\hline B6-0.12g & 19 & $50 \times 50$ & $30 \times 30$ & $50 \times 40$ & 26542 & $0.686 / 1.109$ & $0.251 / 0.280$ & $0.150 / 0.178$ \\
\hline B6-0.23g & 19 & $60 \times 60$ & $40 \times 40$ & $60 \times 40$ & 28430 & $0.450 / 0.628$ & $0.245 / 0.275$ & $0.143 / 0.144$ \\
\hline
\end{tabular}

Periods in Table 1 show regular and expected behavior: (i) cooperation of walls increases clearly stiffness [Cardone 2007], (ii) without walls, stiffness is significantly higher in $x$ direction, (iii) with 
walls, stiffness is similar in both directions, (iv) code-compliant buildings are significantly stiffer, and (v) 6-story buildings are more flexible.

Table 2 describes longitudinal reinforcement amount of columns and wide beams of prototype buildings. In Table 2 indicated reinforcement amounts correspond to both positive and negative bars; in beams, first / second values correspond to end / central sections, respectively.

Table 2. Longitudinal reinforcement amount (\%) of prototype buildings

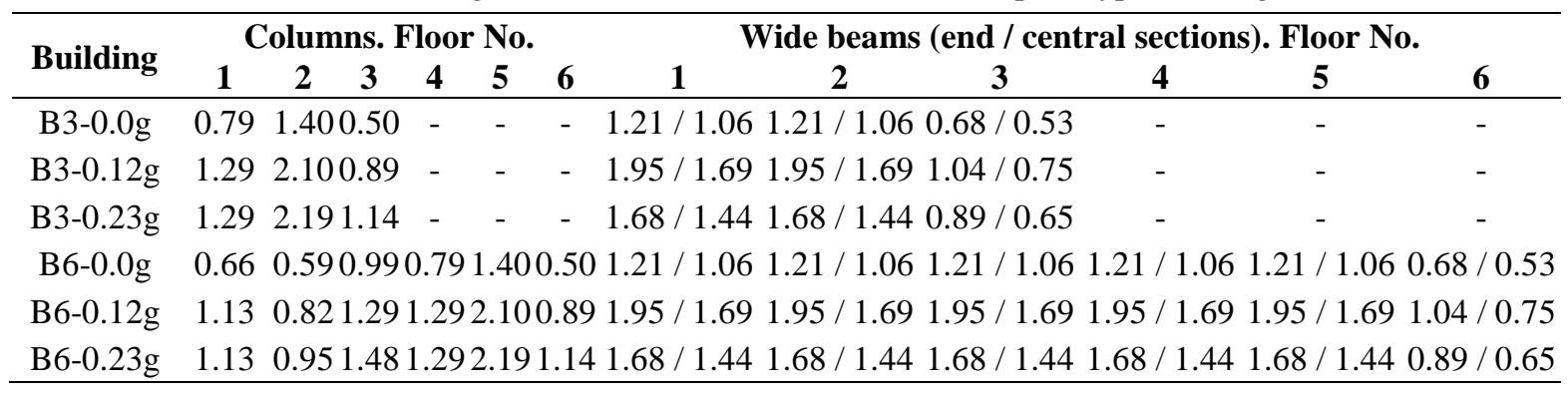

\section{Modeling of behavior of prototype buildings}

\subsection{Structural models}

Structural behavior of buildings in each direction is described with 2D finite element models. Each model includes five frames (Figure 2); rigid fictitious pin-ended bars (represented with dot lines in Figure 16) connect outer nodes of those frames, at each story level, to account for rigid diaphragm effect provided by slabs. Time integration is done using Newmark- $\beta$ method [Newmark 1959] with $\beta=1 / 6$ (linearly varying acceleration method); time step is $0.001 \mathrm{~s}$ and damping is described by a 5\% Rayleigh model. Given the high lateral flexibility of studied buildings, second-order analyses are performed; however, in most cases differences with first-order analyses are small. Derived model is implemented in program IDARC-2D, version 7.0 [Kunnath, Reinhorn 2010].

\subsection{Modeling of frames}

Beams and columns are represented by 2-node frame elements. Connections between columns and wide beams ( $x$ direction) and between columns and façade beams ( $y$ direction) are modeled as rigid, given that reinforcement is satisfactorily anchored [Domínguez 2012]. Conversely, connections between columns and joists ( $y$ direction) are modeled as rigid for negative bending moments and as pinned for positive bending moments, given that lower longitudinal reinforcement bars are not adequately anchored, as shown by Figure 2.d. Stiffness and strength of joists correspond to its rectangular section (Figure 2.e). Bottom floor columns are clamped to foundation.

Concrete and steel behavior is described by uniaxial constitutive laws. Steel stress-strain diagram is trilinear; first branch corresponds to elastic domain, second branch is horizontal (after yielding) and third branch accounts for strain hardening. Concrete constitutive law is parabola-rectangle; tension strength is neglected [EN 1992 2003].

Nonlinear behavior is concentrated in plastic hinges located at both member ends; plastic hinges length ranges between 20 and $30 \mathrm{~cm}$. Hysteretic behavior is described by polygonal hysteretic model (PHM). PHM refers to models based on piecewise linear behavior. A detailed description of general framework for PHMs can be found in [Sivaselvan, Reinhorn 1999]. PHM model uses a non- 
symmetric monotonic envelope defined by elastic stiffness $K_{\mathrm{e}}$, secant stiffness $K_{0}$, cracking moment $M_{\mathrm{c}}$, yield moment $M_{\mathrm{y}}$, curvature-ductility factor $\mu_{\phi}$, and four parameters that control effects of stiffness degradation (HC), strength degradation (HBE, HBD) and pinching (HS) [Reinhorn et al. 2009]. Stiffness degradation is modeled by pivot rule: load-reversal branches target a pivot point on elastic branch whose position is controlled by parameter HC. Strength degradation is modeled reducing capacity in backbone curve according to parameters HBE and HBD accounting for dissipated energy and plastic deformation, respectively. Pinching occurs as a result of crack closure, bond slip and other phenomena. Slip is modeled by stating crack closing point as a target point for loading branch; force corresponding to this point is a fraction of yielding moment being controlled by parameter HS. A more detailed explanation can be found in [Reinhorn et al, 2009]. $M_{\mathrm{y}}$ is determined according to [ACI 318-08 2008], obtained results are calibrated with Response 2000 program [Bentz, Collins 1992], agreement proves satisfactory. Cracking curvature is determined from initial sectional stiffness $K_{\mathrm{e}}$, accounting for contribution of reinforcement. $K_{0}$ is calculated by multiplying initial elastic sectional stiffness of gross sections by an empirical factor taking into account effects of concrete cracking and axial force [Sugano 1968]. Parameters $\mu_{\phi}, \mathrm{HC}$, HBE, HBD and HS are calibrated with previous tests [Benavent-Climent 2007, Benavent-Climent et al. 2009a,b] on one exterior and one interior wide beam-column subassemblies. For wide beams in exterior connections and for façade beams, good fittings are obtained with $\mathrm{HBD}=0, \mathrm{HS}=0.2$, $\mu_{\phi}=12, \mathrm{HC}=2, \mathrm{HBE}=0.6$; for wide beams in interior connections, $\mathrm{HBD}=0, \mathrm{HS}=0.2, \mu_{\phi}=21$, $\mathrm{HC}=3.5, \mathrm{HBE}=0.4$. For exterior columns, $\mathrm{HBD}=0, \mathrm{HS}=0.2, \mu_{\phi}=3, \mathrm{HC}=1.8, \mathrm{HBE}=0.6$; and for interior columns $\mathrm{HBD}=0, \mathrm{HS}=0.2, \mu_{\phi}=3, \mathrm{HC}=3.1, \mathrm{HBE}=0.4$ [Benavent-Climent, Zahran 2010]. Curvature ductility $\mu_{\phi}$ considered for interior wide-beams is similar to the one adopted in [Masi 2003] for flexible beams of post-1970 Italian RC frames designed only for gravity loads $\left(\mu_{\phi}=20\right)$. Moreover, assumed values of $\mu_{\phi}$ provide chord rotation ductility ratios close to those obtained in tests. For joists, $\mathrm{HBD}=0, \mathrm{HS}=0.2, \mathrm{HC}=3.5, \mathrm{HBE}=0.4$; given the lack of experimental results, ductility curvature is conservatively estimated as $\mu_{\phi}=4$. Noticeably, since contribution of joists to transverse lateral resistance is low, it is expected that overall behavior of buildings in transverse direction $(y)$ is not highly sensitive to this parameter. Joint panels are assumed to be infinitely rigid. Values of $\mu_{\phi}$ are identified from experiments on beam-column connections representative of real constructions; therefore, take into account confinement contribution

Methods proposed in [Benavent-Climent 2009a, 2009b] are applied to estimate influence of incomplete torsion capacity of outer zones of wide beams. In both non code-compliant and codecompliant buildings, it is checked that joints do not fail prior than beams or columns; as well, it is verified that, in any section of members, shear failure do not precede flexural one.

\subsection{Modeling of infill walls}

Compression-only bars joining adjacent floors represent masonry infill walls. Their hysteretic behavior is simulated with Bouc-Wen models [Baber, Noori 1985]. Those models provide bilinear behavior, as shown by Figure 4, displaying envelope of shear force $V$ versus lateral displacement $u$. 


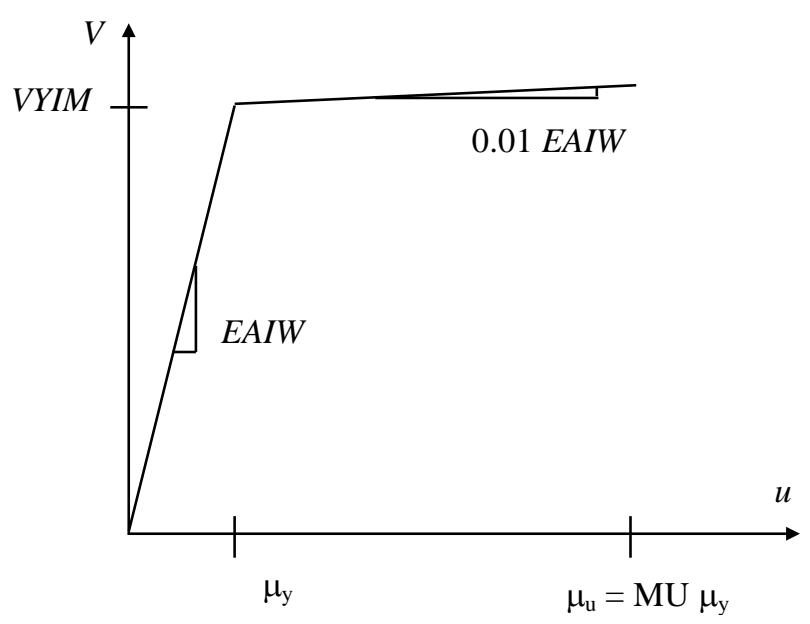

Figure 4. Envelope of shear force vs. lateral displacement for wall modelling

In Figure 4, VYIM is yield force, EAIW is initial stiffness, and MU is displacement ductility. Resistance VYIM is obtained from tie-and-strut models, where two major failure modes are contemplated: diagonal strut compression and horizontal sliding along a course. Resistance is obtained from tie-and-strut models, where two major failure modes are considered: diagonal strut compression and horizontal sliding along a course. In all analyzed cases, resistance for first failure mode is significantly smaller. Parameters for tie-and-strut models are estimated as indicated by Eurocode 6 [EN 1996 2005]. As suggested in [Mostafaei, Kabeyasawa 2004], initial stiffness is estimated as two times ratio between ultimate resistance and displacement. Post-peak behavior is not considered. Wall characteristic strength and secant longitudinal and transverse deformation moduli [Martínez et al. 2001] are

$$
\begin{array}{rl}
f_{\mathrm{k}} & =K f_{\mathrm{b}}^{0.70} f_{\mathrm{m}}^{0.30}=0.45 \times 12^{0.70} \times 8^{0.30}=4.781 \mathrm{MPa} \\
E=500 f_{\mathrm{k}}=2391 \mathrm{MPa} & G=0.4 E=956 \mathrm{MPa}
\end{array}
$$

Coefficient $K$ is chosen according to brick unit type (clay, group 2), mortar type (general purpose) and presence of longitudinal joints. After these results, chosen values of design parameters are VYIW $=352 \mathrm{kN}, \mathrm{EAIW}=56 \mathrm{kN} / \mathrm{mm}$ and $\mathrm{MU}=15$ [Pujol et al. 2008].

Risk of failure of columns due to their interaction with adjoining infill walls is verified. Shortcolumn effects [Mehrabi et al. 1994] are ignored, since length of columns in contact with diagonal struts is rather small [Domínguez 2012], ranging between 0.68 and $0.80 \mathrm{~m}$ [Paulay, Priestley, 1992]. Shear failure of columns generated by diagonal compressive forces is checked by verifying that columns fulfill strength and ductility requirement of Spanish design code [EHE 2008]. It is also checked that columns are able to resist, with safety margin higher than 20\% [EHE 2008], maximum shear forces compatible with plastic moments (determined accounting for actual axial forces) at their end sections.

\section{Pushover analysis of prototype buildings}

Two-dimensional pushover analyses are performed using model described in section 3. Since behavior of infill walls is described with dynamic models, capacity curves are not obtained by static nonlinear analyses but with incremental nonlinear dynamic analyses using a given ground motion record scaled with different factors. Selected input is NS component of Tolmezzo-Diga Ambiesta 
record of Friuli earthquake (06/05/1976) [ESD 2014]. Results obtained with that accelerogram are compared with those calculated with other inputs; agreement is satisfactory, both in terms of forces and displacements [Domínguez 2012]. Moreover, conventional incremental static analyses are performed for buildings without walls; no relevant differences between static and dynamic analyses are observed. For further reliability, results of IDARC program are satisfactorily compared with other results obtained with SeismoStruct code [Seismosoft 2013].

Figure 5 and Figure 6 display capacity curves of 3 and 6-story prototype buildings, respectively. Vertical / horizontal axis represents maximum base shear force / top floor displacement during input duration; both magnitudes occur almost simultaneously. Symbols $\bigcirc$ and $*$ describe level of damage in columns and beams. corresponds to first full development in any plastic hinge and * indicates first failure in any plastic hinge. Full development means that yielding moment is reached and failure corresponds to full hinge (e.g. zero moment, final residual strength is exhausted). For the sake of comparison with time-history analyses under Lorca record, collapse points are defined. Given that walls failure do not imply global collapse and walls fail earlier than frames, it is assumed that final displacement capacity of buildings with and without walls is roughly the same. Therefore, collapse is defined as point of capacity curves (for building without walls) right before final descending branch. In all curves in Figure 5 and Figure 6 except Figure 6.b, collapse point coincides with first failure (*). In Figure 6.b, absence of symbol $*$ is due to premature analysis termination.

Plots from Figure 5 and Figure 6 show regular and expected behavior. Main observations are:

- Comparison between no walls, low wall density and high wall density. Walls increase significantly initial stiffness [Cardone 2007], this being coherent with values of fundamental periods displayed in Table 1. In terms of displacement, walls fail earlier than main frame, as shown by after-peak descendant branches of buildings with walls. However, for larger displacements, such branches converge with corresponding curves of buildings without walls. This convergence can be read as complete vanishing of walls capacity. As expected, points are situated approximately in same vertical, regardless of wall density.

- Comparison between $\boldsymbol{x}$ and $\boldsymbol{y}$ directions. As expected, in $x$ and $y$ directions capacity curves for buildings without walls are different, but those of buildings with walls are similar, since important capacity and stiffness of walls govern behavior.

- Comparison between $0.0 \mathrm{~g}, 0.12 \mathrm{~g}$ and $0.23 \mathrm{~g}$. In terms of forces, capacity of buildings with walls is similar, since their contribution clearly exceeds the one of main frame. Regarding buildings without walls, those designed without seismic provision (B3-0.0g and B6-0.0g) exhibit slightly smaller resistance; however, higher strength of buildings B3-0.12g, B6-0.12g, B3-0.23g and B6-0.23g hardly compensates their greater weight. For any wall density, displacement ductility is not clearly correlated to design PGA.

- Comparison between 3 and 6-story buildings. Resisted base shear coefficient is smaller in 6story buildings; conversely, displacement ductility is rather similar.

\section{Lorca earthquake}

\subsection{Principal characteristics of Lorca earthquake}

2011 Lorca earthquake (11-05-2011) is most damaging seismic event recorded in Spain [IGN 2011]. Its magnitude is rather moderate $\left(M_{\mathrm{w}}=5.1\right.$; [IGME 2011]), therefore, intensity is mostly contributed by other circumstances, as extremely shallow hypocenter (hypocentral depth is estimated as $2 \mathrm{~km}$ ), high proximity between epicenter and city center ( $2.9 \mathrm{~km}$ to seismologic 
station) and ensuing near-fault effects. Figure 7 displays most severe accelerograms [IGN 2011]; those inputs were recorded in stiff soil, characterized by $v_{\mathrm{s}, 30}$ between 360 and $800 \mathrm{~m} / \mathrm{s}$. Maximum acceleration of NS component is approximately $0.37 \mathrm{~g}$, more than three times PGA prescribed for Lorca by Spanish design code (0.12 g) [NSCE-02 2002].

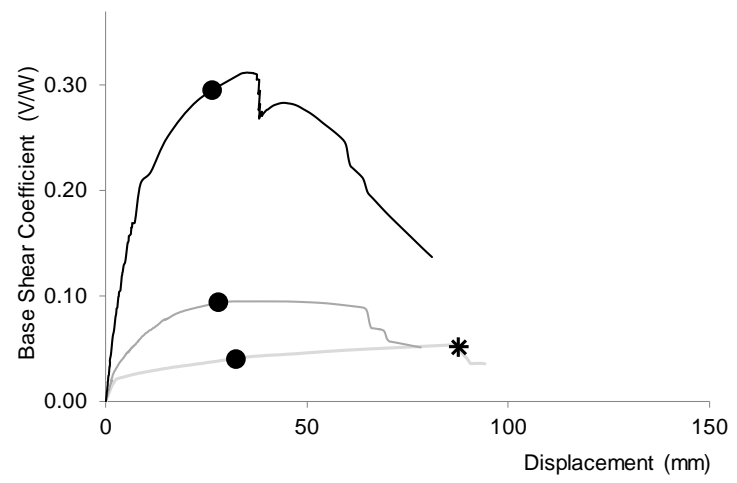

(a) Building B3-0.0g. Wide beams direction $(x)$

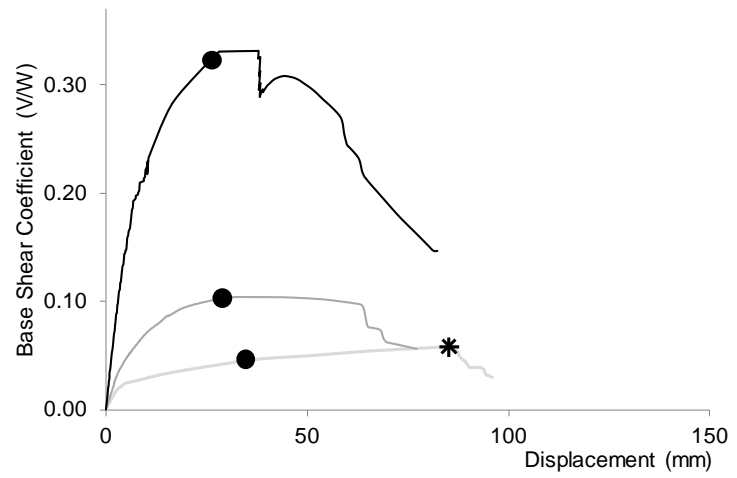

(c) Building B3-0.12g. Wide beams direction (x)

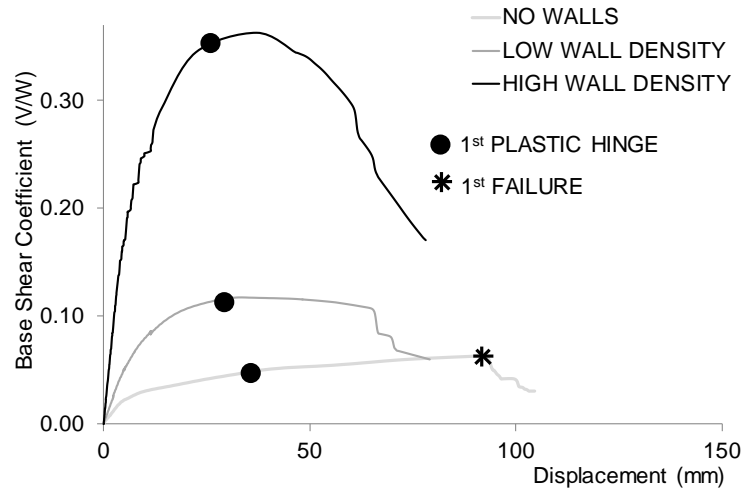

(e) Building B3-0.23g. Wide beams direction $(x)$

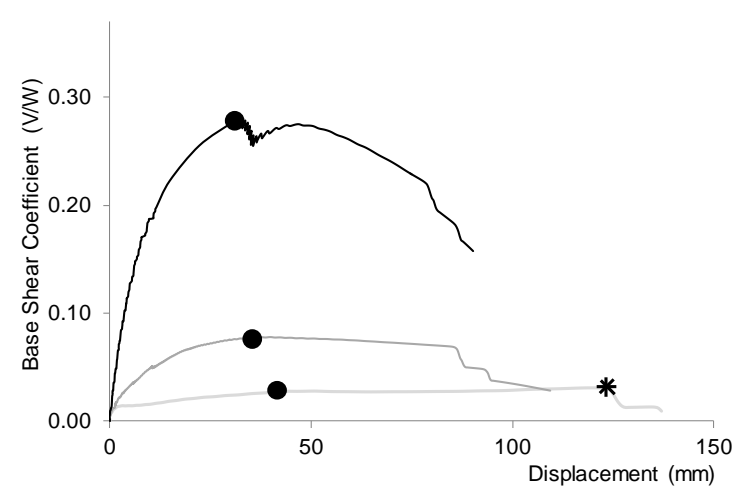

(b) Building B3-0.0g. Transverse direction $(y)$

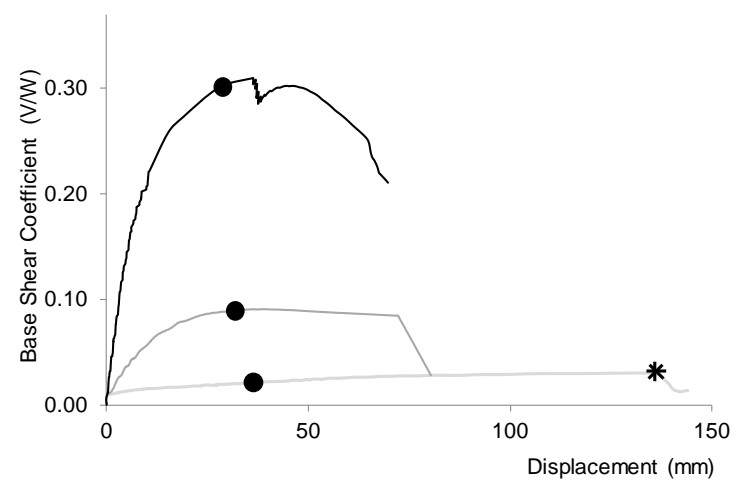

(d) Building B3-0.12g. Transverse direction (y)

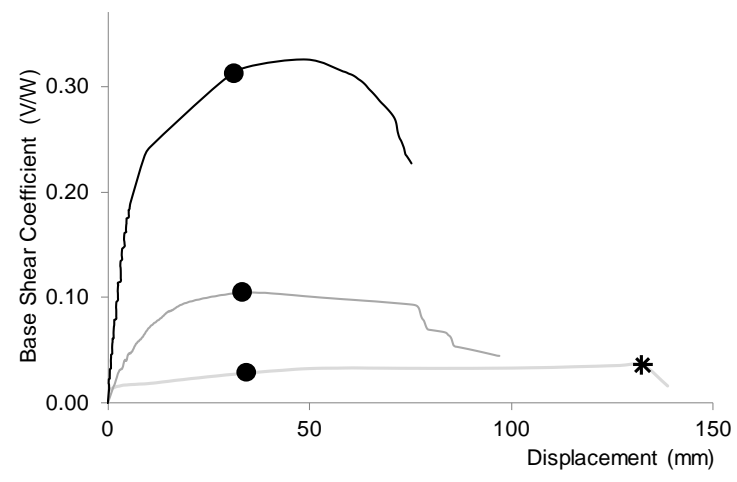

(f) Building B3-0.23g. Transverse direction (y)

Figure 5. Capacity curves of 3-story prototype buildings

Table 3 depicts most relevant characteristics of selected records. $I_{\mathrm{A}}$ is Arias Intensity [Arias 1970] given by $I_{\mathrm{A}}=\frac{\pi}{2 g} \int \ddot{x}_{\mathrm{g}}^{2} d t$ where $\ddot{x}_{\mathrm{g}}$ is input ground acceleration; Arias intensity quantifies input 
severity. $I_{\mathrm{D}}$ is dimensionless seismic index [Manfredi 2001] given by $I_{\mathrm{D}}=\frac{\int \ddot{x}_{\mathrm{g}}^{2} d t}{P G A P G V} . I_{\mathrm{D}}$ accounts broadly for velocity pulses content; small / big values of $I_{\mathrm{D}}$ correspond to records with / without pulses. PI is pulse index [Baker 2007], which ranges between 0 and 1; records with scores above 0.85 and below 0.15 are classified as pulses and non-pulses, respectively. $E_{\mathrm{p}}$ is relative pulse energy [Zhai et al. 2013], representing portion of ground motion energy that corresponds to pulse; pulse is extracted by peak-point method [Dickinson, Gavin 2011]. Values of $E_{\mathrm{p}}$ greater than 0.3 correspond to pulse-like records and values equal to or below 0.3 are ambiguous. Trifunac duration is time elapsed between 5\% and 95\% of Arias Intensity [Trifunac, Brady 1975]. Bracket duration [Kempton, Stewart 2006] is time elapsed between instants when $5 \%$ of maximum acceleration is exceeded for first and last time, respectively. Table 3 shows that Lorca accelerograms are clearly pulse-like. Comparison between NS and EW components highlights relevant directivity effects already underlined by previous studies [Martínez-Díaz et al. 2012; López-Comino et al. 2013]. 


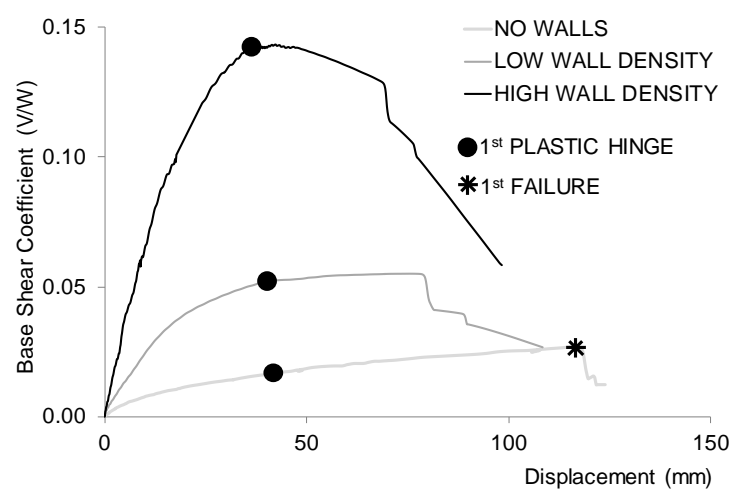

(a) Building B6-0.0g. Wide beams direction $(x)$

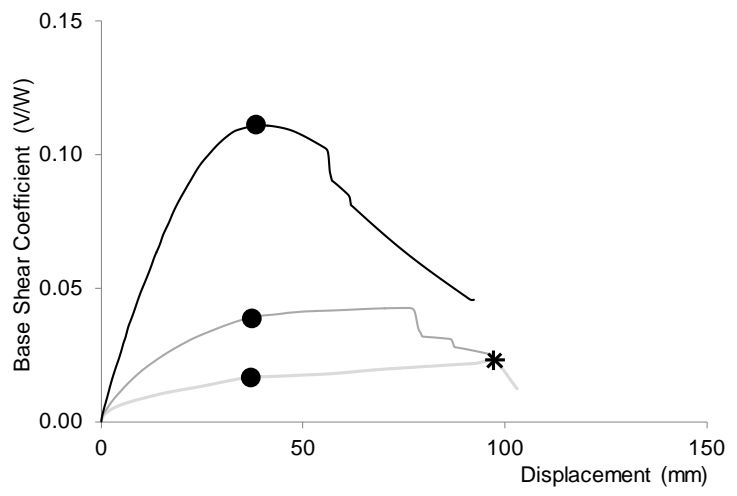

(c) Building B6-0.12g. Wide beams direction (x)

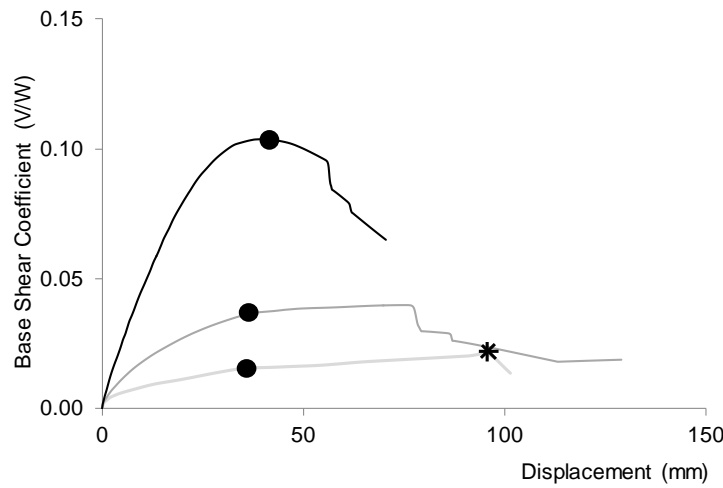

(e) Building B6-0.23g. Wide beams direction $(x)$

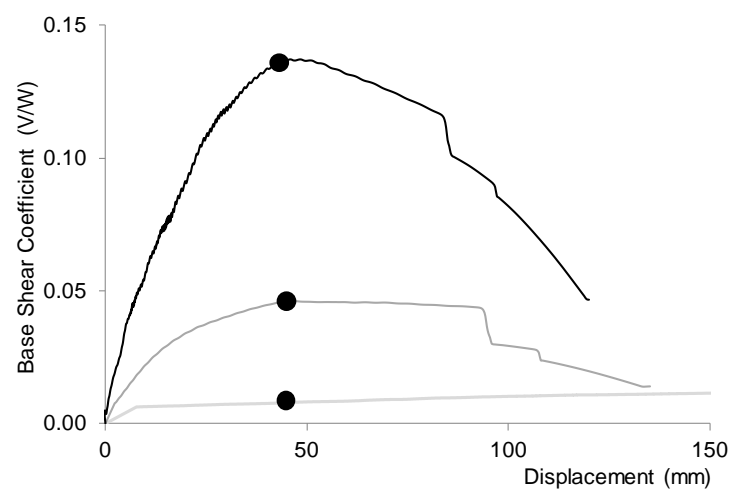

(b) Building B6-0.0g. Transverse direction (y)

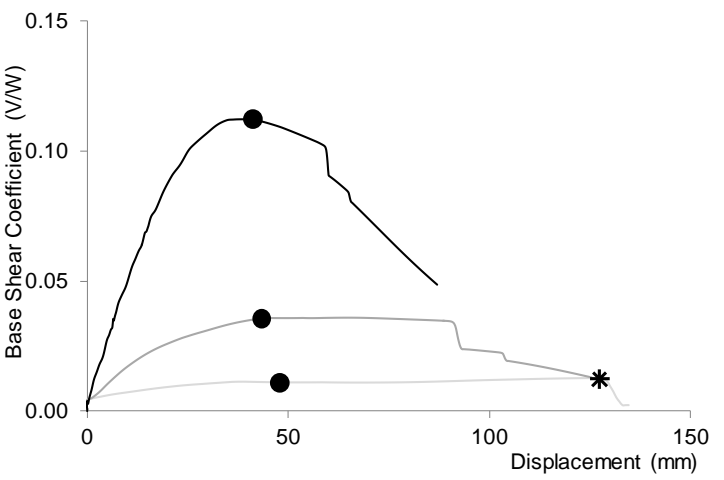

(d) Building B6-0.12g. Transverse direction (y)

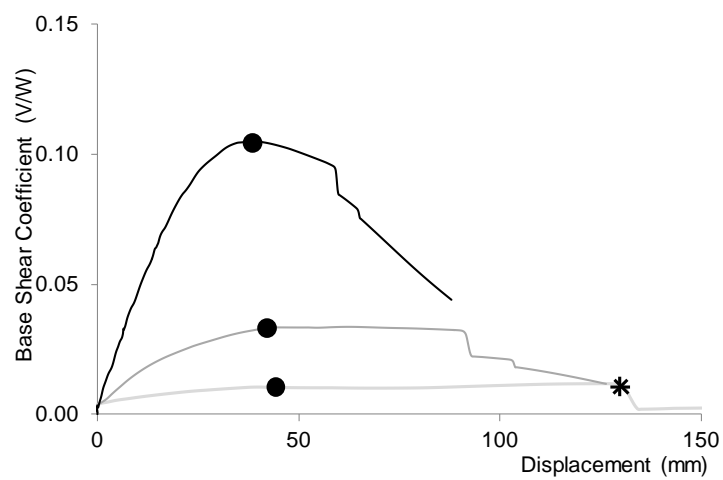

(f) Building B6-0.23g. Transverse direction (y)

Figure 6. Capacity curves of 6-story prototype buildings
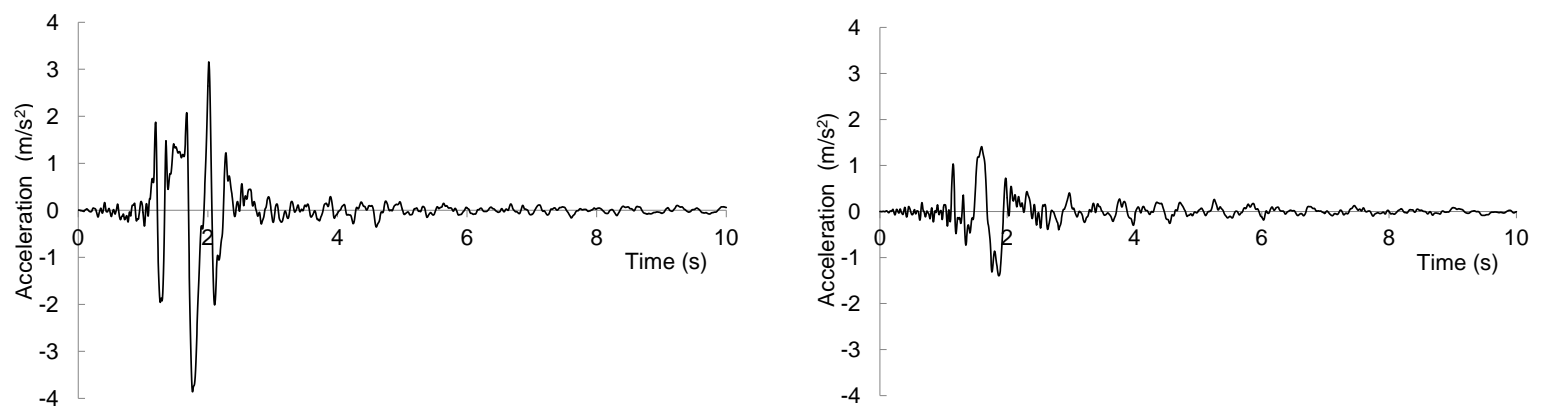
Figure 7. Accelerograms of Lorca earthquake (11-05-2011)

Table 3. Major characteristics of Lorca earthquake records (11-05-2011)

\begin{tabular}{ccccccccc}
\hline Component & $\begin{array}{c}\text { PGA } \\
{\left[\mathbf{m} / \mathbf{s}^{\mathbf{2}}\right]}\end{array}$ & $\begin{array}{c}\mathbf{P G V} \\
{[\mathbf{m} / \mathbf{s}]}\end{array}$ & $\begin{array}{c}\boldsymbol{I}_{\mathbf{A}} \\
{[\mathbf{m} / \mathbf{s}]}\end{array}$ & $\boldsymbol{I}_{\mathbf{D}}$ & $\boldsymbol{P I}$ & $\boldsymbol{E}_{\mathbf{p}}$ & $\begin{array}{c}\text { Trifunac } \\
\text { duration [s] }\end{array}$ & $\begin{array}{c}\text { Bracket } \\
\text { duration [s] }\end{array}$ \\
\hline NS & 3.920 & 0.331 & 0.527 & 2.57 & 0.9995 & 0.72 & 1.005 & 4.035 \\
EW & 1.409 & 0.147 & 0.117 & 3.53 & 0.912 & 0.63 & 3.825 & 14.215 \\
\hline
\end{tabular}

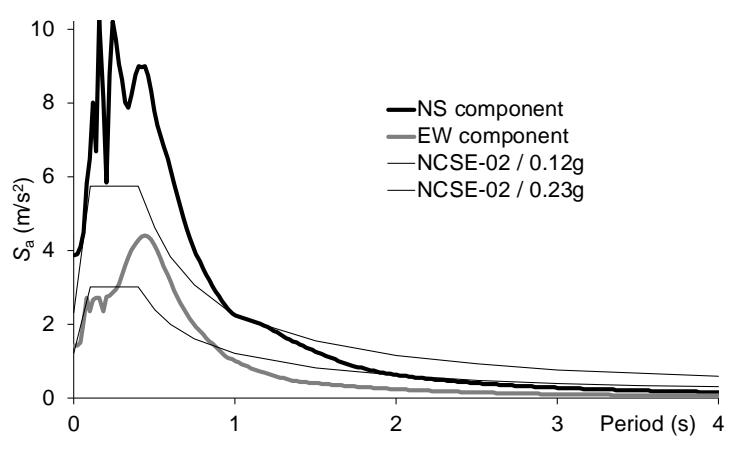

(a) Absolute acceleration spectra

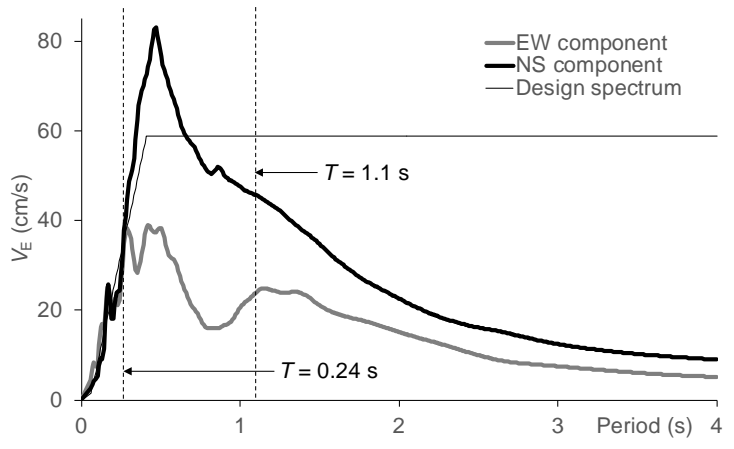

(b) Input energy spectra in terms of velocity [Benavent-Climent et al. 2013]

Figure 8. Response spectra of accelerograms of Lorca earthquake

Significant severity of Lorca earthquake can be also highlighted by its response spectra. Figure 8 displays response spectra of accelerograms in Figure 7. Figure 8.a represents absolute acceleration response spectra $\left(S_{\mathrm{a}}\right)$ [Domínguez 2012] and Figure 8.b displays input energy spectra in terms of velocity $\left(V_{\mathrm{E}}\right)$ [Benavent-Climent et al. 2013]. Design response spectra from Spanish code [NCSE02 2002] for Lorca (0.12 g) and Granada (0.23 g) are also plotted in Figure 8.a.; comparison shows that demanding NS spectral ordinates clearly exceed design ones for virtually all periods of interest. Analogously, in Figure 8.b, a design spectrum previously derived for Spain [Benavent-Climent et al. 2002] is also plotted; comparison with obtained spectra shows that agreement among initial branches is satisfactory and that NS component peak significantly exceeds plateau ordinate. Noticeably, this design spectrum is significantly more demanding than Spanish code [NSCE-02 2002].

High intensity of Lorca earthquake confirms practical interest of analyzing its effect on performance of widespread and potentially vulnerable buildings.

\subsection{Aftermath}

Effects of Lorca earthquake were serious. It caused 9 fatalities, 167 injured (3 severe), 40000 homeless, and important material losses: nearly $80 \%$ of buildings in Lorca city (less than $5 \mathrm{~km}$ away from epicenter) were significantly affected. Most damage concentrated on 2-story and ancient stone masonry heritage buildings; many had been designed without any seismic provision. Among buildings with more than two stories, most common structure is reinforced concrete frames without structural walls. Infill masonry walls are not separated from main structure, thus influencing lateral structural behavior. In actual buildings, there are several patterns of walls distribution; in some cases, first floor does not have walls (pilotis configuration) and subsequent soft-story mechanism 
led to severe damages. Globally speaking, RC wide-beam buildings without pilotis configuration (e.g. infill walls continuous down to foundation) experienced less severe damage; such damage affected both structural and non-structural elements. An important number of such buildings had been designed following recent seismic codes. Works [Benavent-Climent et al. 2012, 2013] contain deep assessments of observed damage.

Some issues of Lorca earthquake require deeper analysis. Just one building actually collapsed, without casualties; all fatalities and virtually all injured were caused by falling debris impact. An explanation follows. Main shake was preceded by a weaker foreshock $\left(M_{\mathrm{w}}=4.6\right)$ trailed by a number of minor aftershocks; then, after less than two hours, main shake $\left(M_{\mathrm{w}}=5.1\right)$ came. Foreshock pushed people out of their homes and minor aftershocks prevented them from reentering; unfortunately, most people remained on side of buildings, thus being hit by falling nonstructural cladding elements.

\subsection{Published research}

Apart from timely reports [Cabañas et al. 2011; Feriche et al. 2011; Goula et al. 2011; IGME 2011; IGN 2011], a relevant number of studies on Lorca earthquake have been published. Some papers have focused on seismological issues [Vissers, Meijninger 2011; López-Comino et al. 2012; Martínez-Díaz et al. 2012]; papers dealing with structural aspects are more relevant to this work and are discussed next.

- Feriche et al. 2012. This work describes damage in 22 buildings; 18 are 3- to 11-story reinforced concrete buildings and 4 are 2- to 4-story brick masonry buildings. This work emphasizes consequences of common design mistakes: vertical irregularity, soft first story, horizontal asymmetry, unaligned slabs, short columns, insufficient transverse reinforcement, pounding, among other issues.

- Benavent-Climent et al. 2012, 2013. These works assess expected damage on buildings subjected to Lorca earthquake through an energy-based approach and nonlinear dynamic analyses. It is highlighted that many of damaged structures are RC frames with wide beams. Influence of pilotis configuration with masonry infill walls is further investigated. It is found that pilotis masonry infill walls makes structure highly prone to damage concentration and reduces overall seismic capacity. As well, a proper strong column-weak beam mechanism and adequate counter-measures to avoid interaction between infill walls and main frame, would have reduced damage significantly.

- De Luca et al. 2013. This work discusses structural role played by masonry infills on RC buildings under Lorca earthquake. Observed damage and numerical analyses show that masonry infills provided additional strength to RC buildings.

- Hermanns et al. 2013. This paper deals with seismic performance, during Lorca earthquake, of 3- to 8-story buildings with masonry infill walls. It is stated that pieces of façades of several buildings fell down, killing 9 people. Masonry walls suffered important damage causing failure of some columns. Structural behavior is analyzed with non-linear Finite Element Models; in light of obtained results, observed failure patterns are explained.

- Vidal et al. 2013. This paper investigates changes in fundamental period and damping ratio of a number of low-to-medium rise Lorca RC buildings from pre- and post-earthquake ambient vibration data. Measurements show a significant after-quake period elongation; conversely, damping ratio keeps rather constant.

- Navarro et al. 2014. This paper studies shallow geology of Lorca and correlates it with observed damage. It is concluded that damage is specially concentrated in areas where soil period is between 0.3 and $0.5 \mathrm{~s}$ and that seismic demand has been high for buildings with 4 to 6 
stories.

- Gómez-Martínez et al. 2015. This work concludes that most losses were caused by nonstructural damage and that masonry infill walls provided additional strength to reinforced concrete buildings.

- Salgado-Gálvez et al. 2015. A probabilistic seismic risk assessment is performed for buildings of Lorca. A building-by-building resolution level is used allowing generation of risk maps.

\section{Behavior of prototype buildings under Lorca earthquake}

\subsection{Relative displacement response}

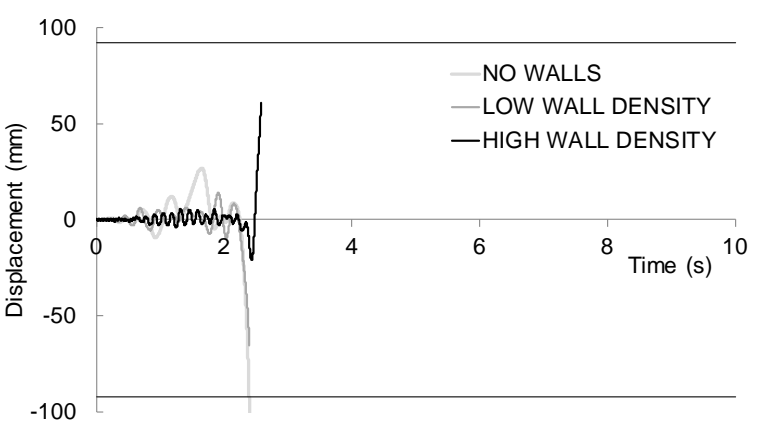

(a) NS component. Wide beams direction $(x)$

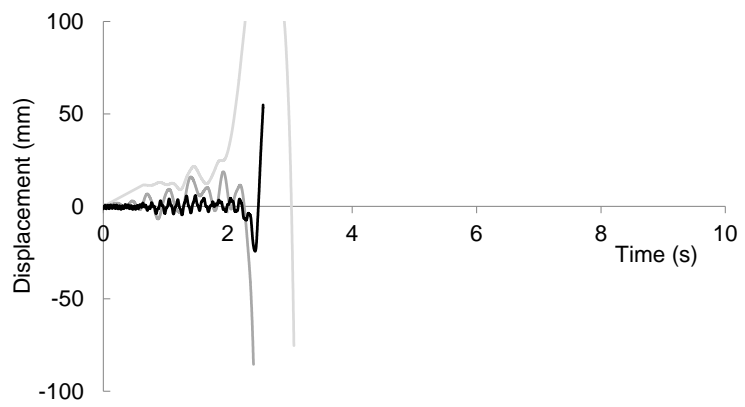

(c) NS component. Transverse direction $(y)$

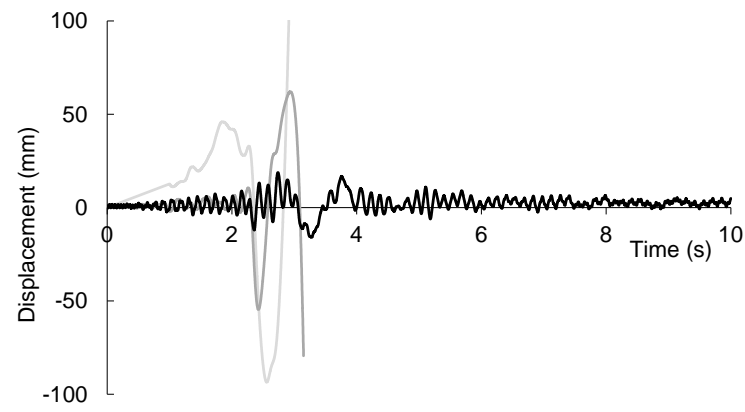

(b) EW component. Transverse direction $(y)$

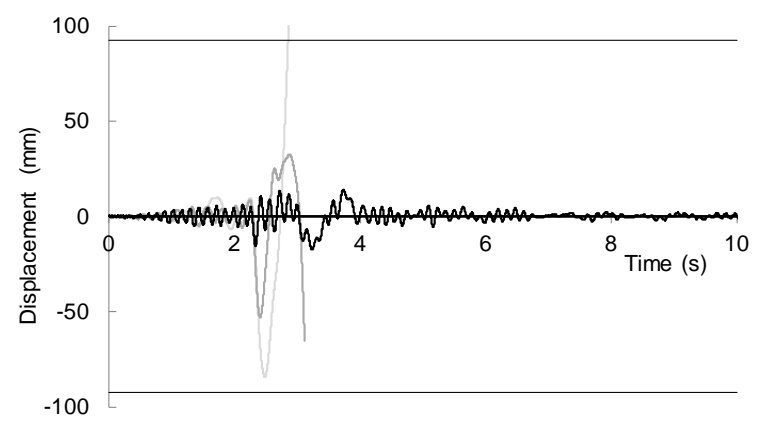

(d) EW component. Wide beams direction $(x)$

Figure 9. Top floor relative displacement response of non-code-compliant building B3-0.0g

Figure 9 through Figure 14 display, for prototype buildings (Table 1), time histories of displacements of upper floors relative to building base. Each component of Lorca earthquake (Figure 7) is applied separately. In Figures \#.a and \#.b (\# represents any number between 9 and 14), buildings are oriented with wide beams in NS direction; in Figures \#.c and \#.d, buildings are rotated $90^{\circ}$. Where collapse displacements from capacity curves in Figure 5 and Figure 6 lie in range of vertical axis, are also plotted as upper and lower bounds. 


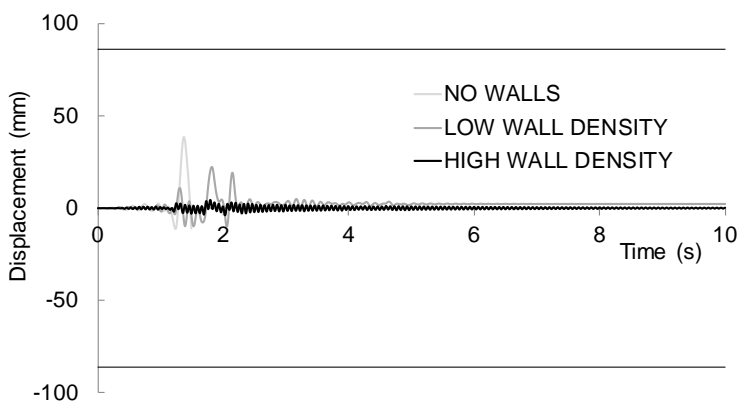

(a) NS component. Wide beams direction $(x)$

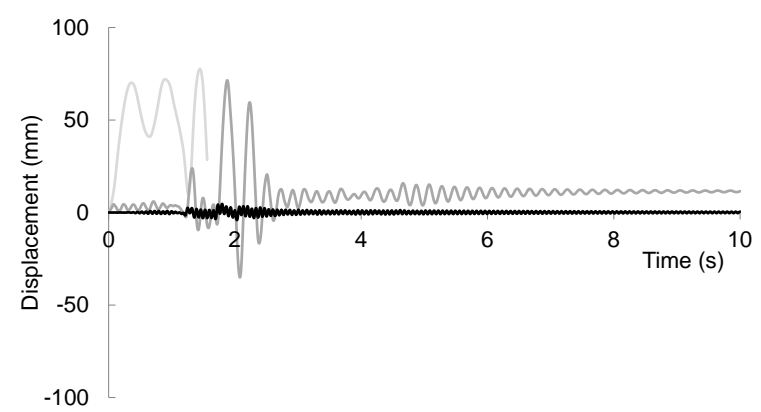

(c) NS component. Transverse direction (y)

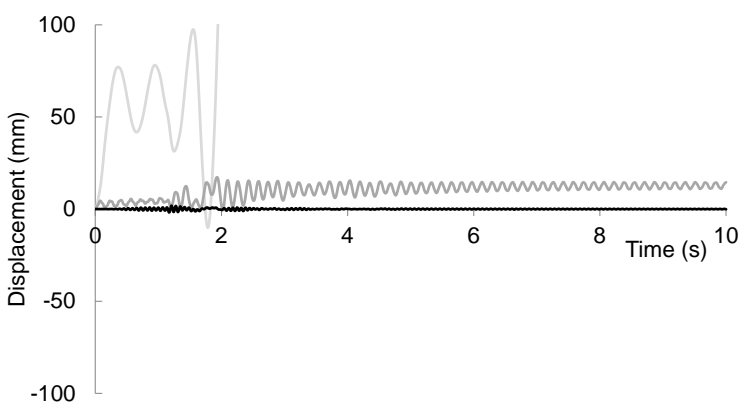

(b) EW component. Transverse direction $(y)$



(d) EW component. Wide beams direction $(x)$

Figure 10. Top floor relative displacement response of code-compliant building B3-0.12g

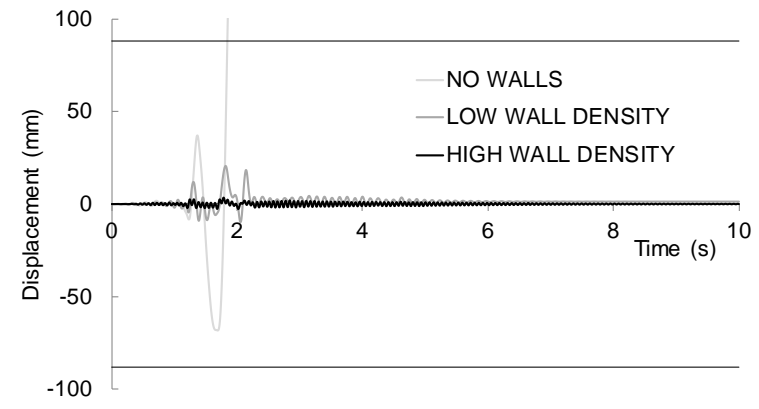

(a) NS component. Wide beams direction $(x)$

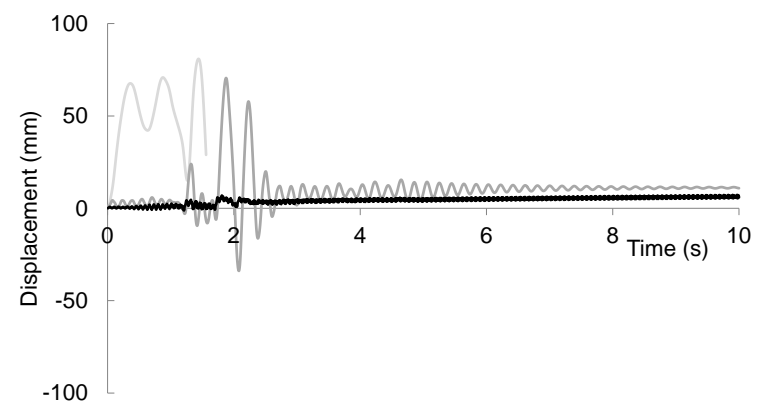

(c) NS component. Transverse direction (y)

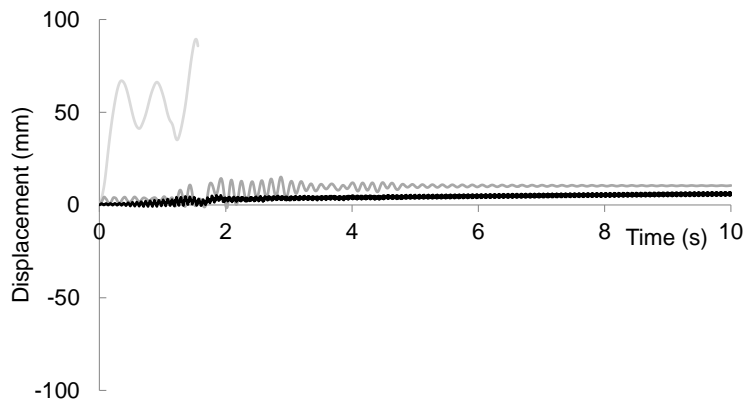

(b) EW component. Transverse direction (y)

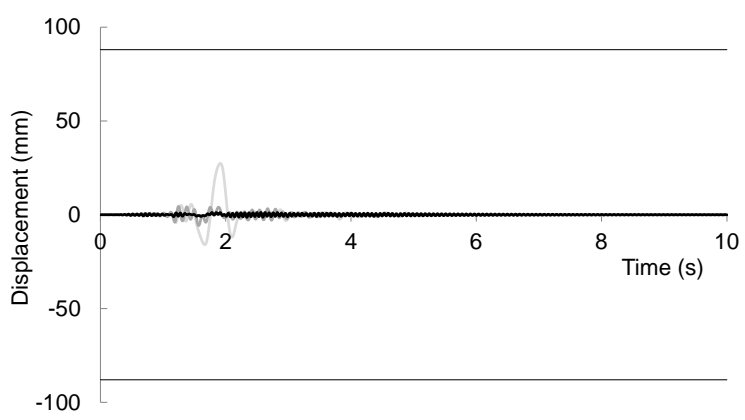

(d) EW component. Wide beams direction ( $x$ )

Figure 11. Top floor relative displacement response of code-compliant building B3-0.23g 


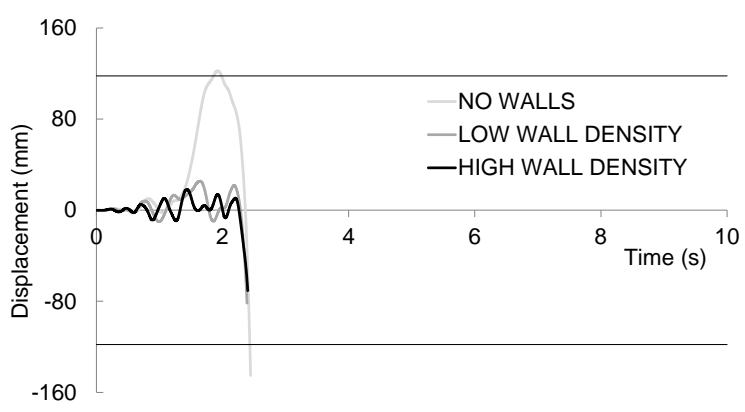

(a) NS component. Wide beams direction $(x)$

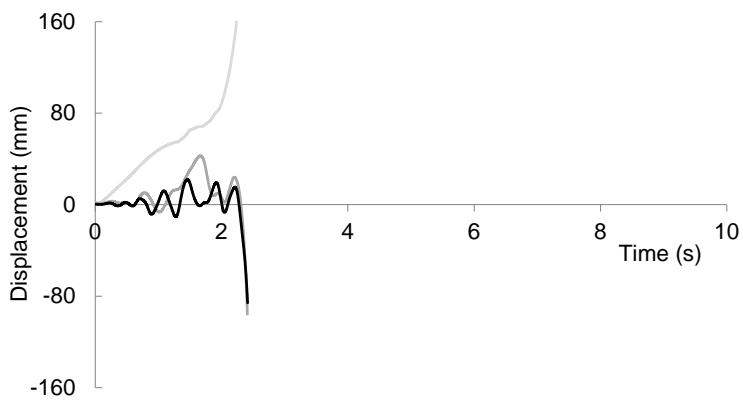

(c) NS component. Transverse direction $(y)$

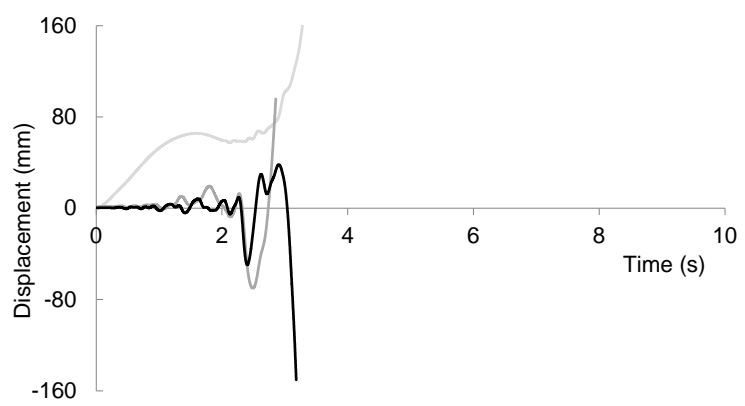

(b) EW component. Transverse direction $(y)$

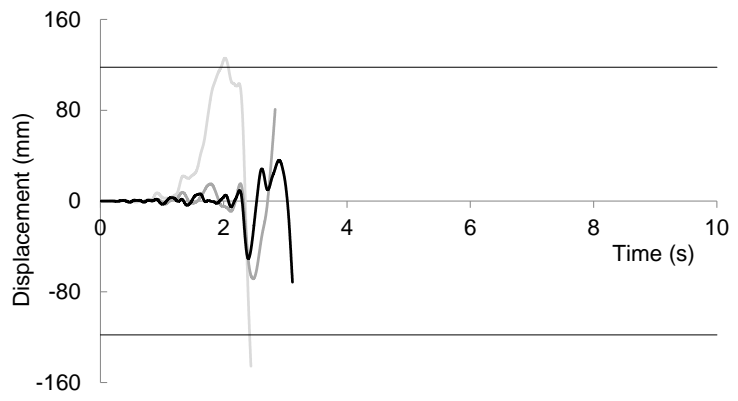

(d) EW component. Wide beams direction $(x)$

Figure 12. Top floor relative displacement response of non-code-compliant building B6-0.0g

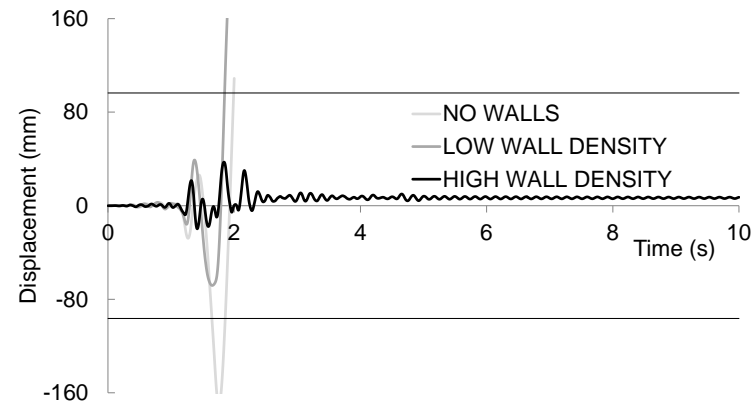

(a) NS component. Wide beams direction $(x)$

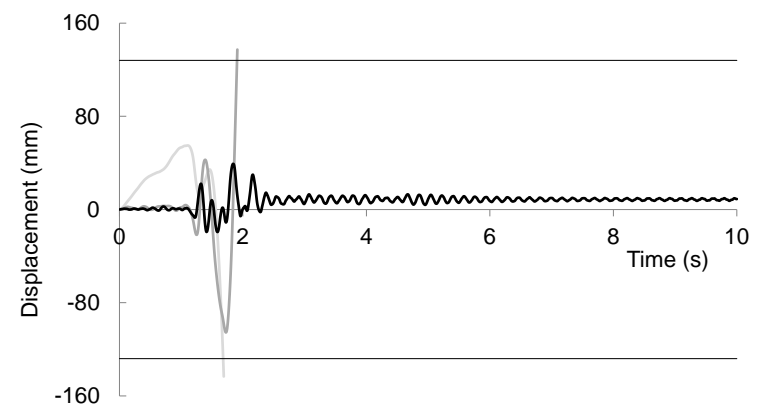

(c) NS component. Transverse direction (y)

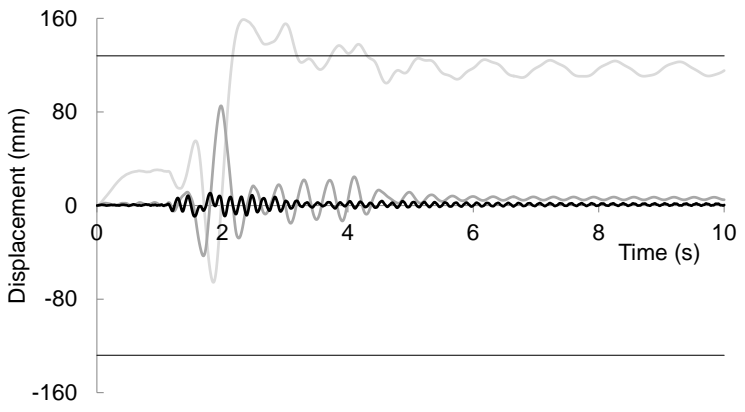

(b) EW component. Transverse direction (y)

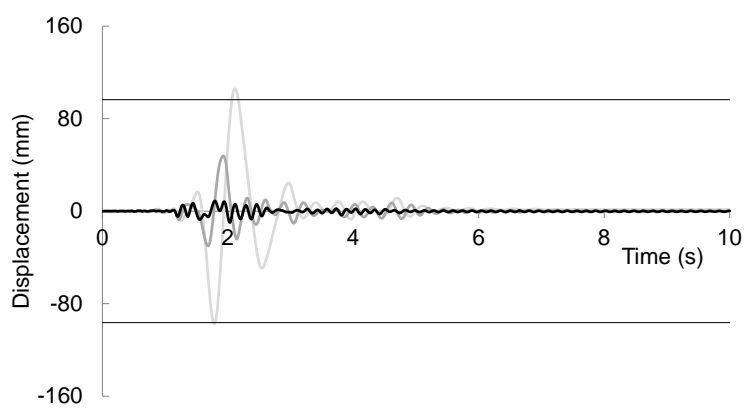

(d) EW component. Wide beams direction ( $x$ )

Figure 13. Top floor relative displacement response of code-compliant building B6-0.12g 


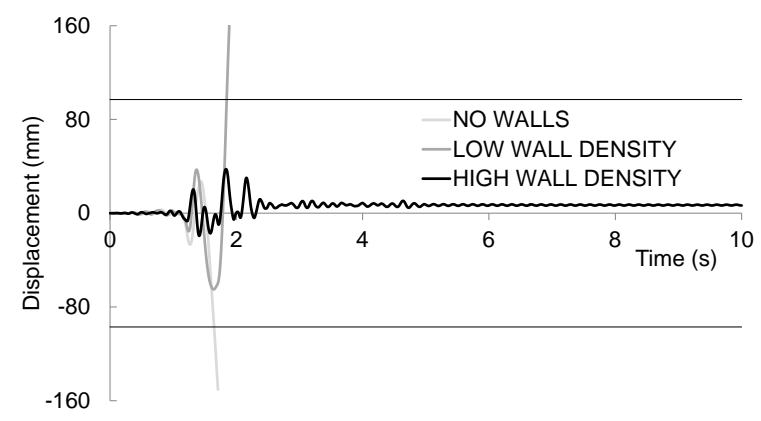

(a) NS component. Wide beams direction $(x)$

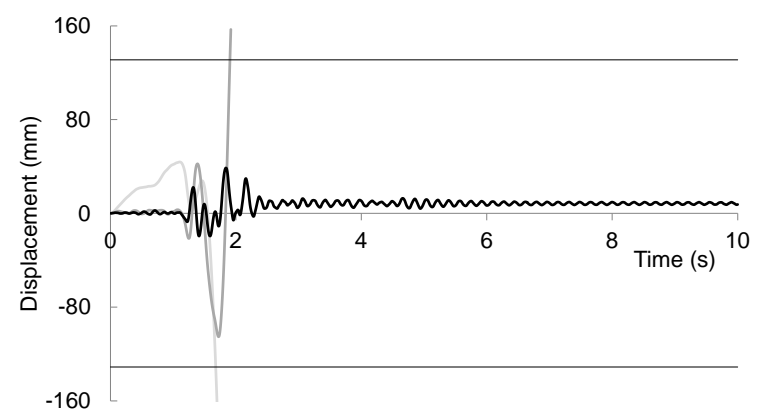

(c) NS component. Transverse direction (y)

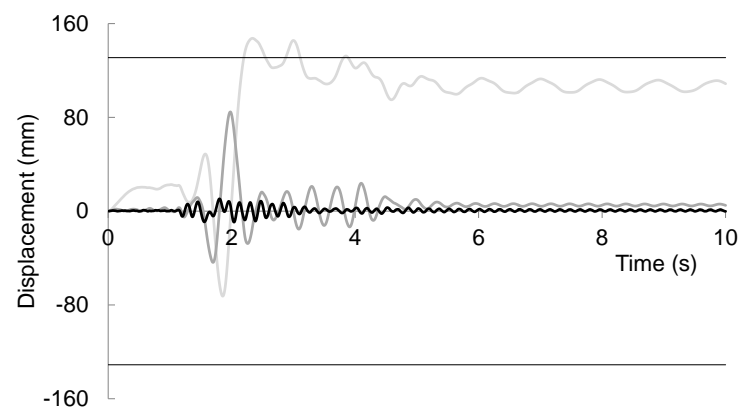

(b) EW component. Transverse direction $(y)$

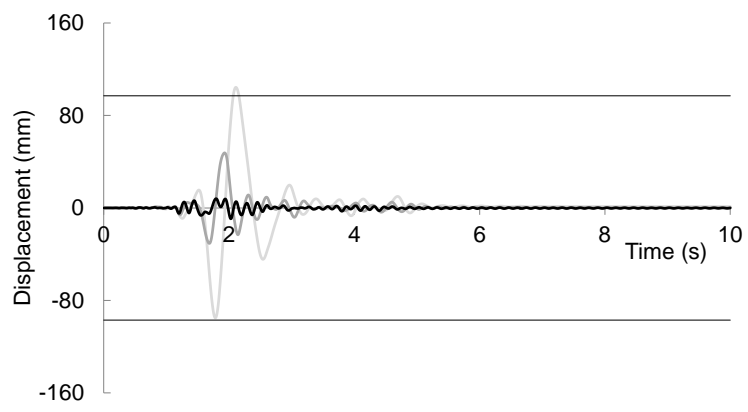

(d) EW component. Wide beams direction $(x)$

Figure 14. Top floor relative displacement response of code-compliant building B6-0.23g

Table 4 summarizes results displayed in Figure 9 through Figure 14. Table 4 displays ratios between top floor maximum displacement relative to building base and maximum displacement capacity (points * in Figure 5 and Figure 6). Collapse situations are represented as “-”. Figures higher than 1 in Table 4 can be explained by different assumptions in capacity curves and in timehistories.

Table 4. Ratios between top floor maximum relative displacement and maximum displacement capacity

\begin{tabular}{|c|c|c|c|c|c|c|c|c|c|c|c|c|}
\hline \multirow{2}{*}{ Building } & \multicolumn{4}{|c|}{ No walls } & \multicolumn{4}{|c|}{ Low wall density } & \multicolumn{4}{|c|}{ High wall density } \\
\hline & NS / $x$ & $\mathrm{EW} / \mathrm{y}$ & NS / y & $\mathbf{E W} / x$ & NS / $x$ & $\mathrm{EW} / \mathrm{y}$ & NS / y & $\mathbf{E W} / \boldsymbol{x}$ & NS / $x$ & $\mathrm{EW} / \mathrm{y}$ & NS / y & $\mathrm{EW} / \boldsymbol{x}$ \\
\hline B3-0.0g & - & - & - & - & - & - & - & - & - & 0.108 & - & 0.150 \\
\hline B3-0.12g & 0.416 & - & - & 0.622 & 0.241 & 0.129 & 0.534 & 0.087 & 0.048 & 0.014 & 0.034 & 0.017 \\
\hline B3-0.23g & - & - & - & 0.316 & 0.237 & 0.124 & 0.578 & 0.067 & 0.039 & 0.056 & 0.027 & 0.016 \\
\hline B6-0.0g & - & - & - & - & - & - & - & - & - & - & - & - \\
\hline B6-0.12g & - & 1.262 & - & 1.085 & - & 0.677 & - & 0.488 & 0.382 & 0.083 & 0.311 & 0.101 \\
\hline B6-0.23g & - & 1.122 & - & 1.082 & - & 0.639 & - & 0.495 & 0.387 & 0.080 & 0.296 & 0.098 \\
\hline
\end{tabular}

Time-histories displayed in Figure 9 through Figure 14 and figures in Table 4 show regular behavior. Indeed, displacements are higher in: (i) 6-story buildings, (ii) buildings with less walls and smaller design acceleration, (iii) weakest direction $(y$ ), and (iv) under strongest component (NS). Beyond these obvious observations, major remarks are:

- Buildings without walls. Not any building survives Lorca input in both directions.

- Buildings with low wall density. 3-story buildings without seismic provisions (B3-0.0g) collapse in both directions. 3-story buildings with seismic provisions (B3-0.12g and B3-0.23g) resist Lorca input with moderate damage in columns and beams (Park \& Ang damage index [Park, Ang 1985] ranges between 0.03 and 0.485), although walls in direction of strongest 
component (NS) might collapse; this last statement is supported by comparison with capacity curves shown in Figure 5. 6-story buildings (B6-0.0g, B6-0.12g and B6-0.23g) collapse, at least in one direction.

- Buildings with high wall density. Buildings without seismic provisions (B3-0.0g and B6-0.0g) collapse, at least in one direction. Buildings with seismic provisions (B3-0.12g, B3-0.23g, B6$0.12 \mathrm{~g}$ and B6-0.23g) resist Lorca input with no or moderate damage in columns and beams (Park \& Ang damage index ranges between zero and 0.235); in buildings B6-0.12g and B60.23 g, walls in direction of strongest component (NS) might experience serious damage. This last statement relies on capacity curves displayed in Figure 5 and Figure 6.

\subsection{Absolute acceleration response}

As discussed in subsection 5.2, all fatalities and most of injured were caused by detachment of untied cladding elements. Therefore, absolute acceleration response is of primary importance. Figure 15 displays time histories of absolute accelerations of top floor of building B3-0.23g.

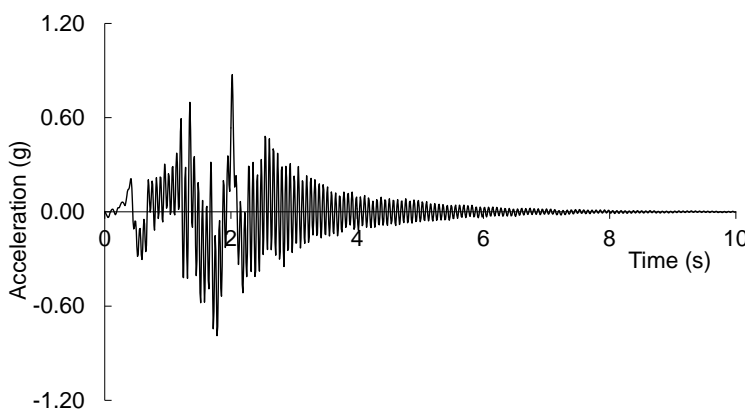

(a) NS component. Wide beams direction $(x)$

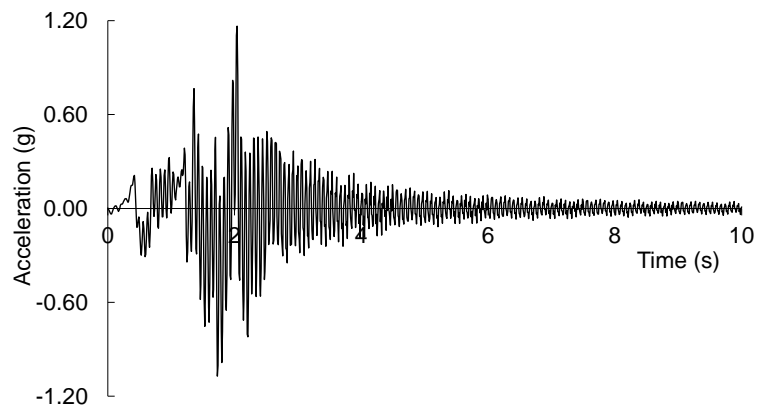

(c) NS component. Transverse direction (y)

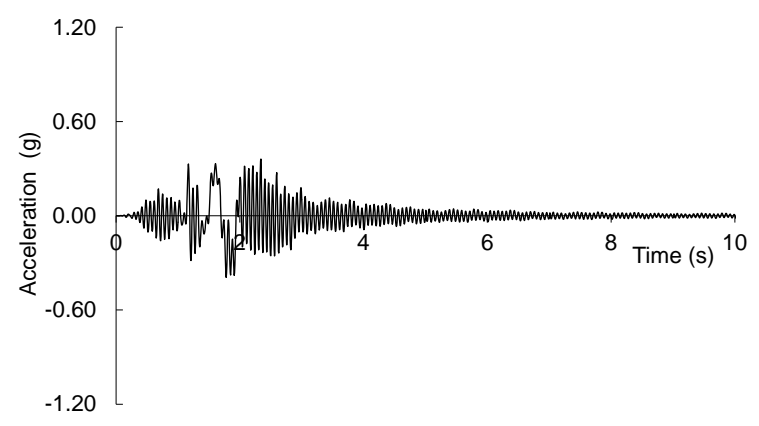

(b) EW component. Transverse direction (y)

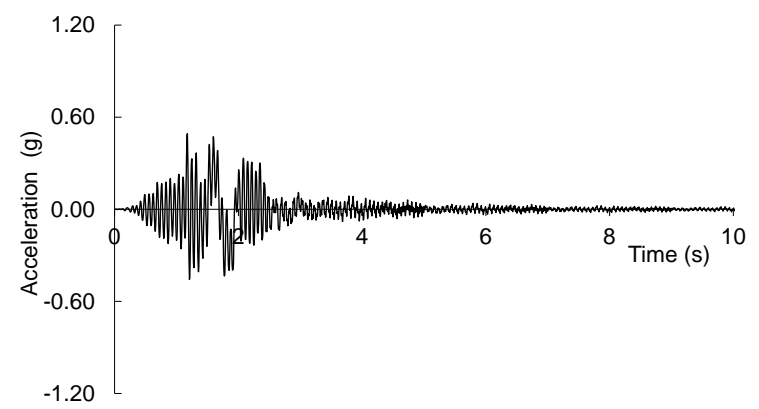

(d) EW component. Wide beams direction $(x)$

Figure 15. Top floor absolute acceleration response of code-compliant building B3-0.23g with high wall density 
Table 5. Top floor maximum absolute accelerations (g)

\begin{tabular}{|c|c|c|c|c|c|c|c|c|c|c|c|c|}
\hline \multirow{2}{*}{ Building } & \multicolumn{4}{|c|}{ No walls } & \multicolumn{4}{|c|}{ Low wall density } & \multicolumn{4}{|c|}{ High wall density } \\
\hline & NS / $x$ & $\mathrm{EW} / \mathrm{y}$ & NS / y & $\mathbf{E W} / \boldsymbol{x}$ & IS $/ x$ & $\mathrm{EW} / \mathrm{y}$ & NS / y & $\mathbf{E W} / x$ & NS $/ x$ & $\mathbf{E W} / \mathbf{y}$ & NS / y & $\mathbf{E W} / x$ \\
\hline B3-0.0g & - & - & - & - & - & - & - & - & - & 0.501 & - & 0.392 \\
\hline B3-0 & - & - & - & & & & & & & 0.398 & & .335 \\
\hline B3-0. & - & - & - & & 0.563 & 0.358 & 0.708 & 0.319 & 0.734 & 1.860 & 2.120 & 0.393 \\
\hline B6-0.0g & - & - & - & - & - & - & - & - & - & - & - & - \\
\hline B6-0.12g & - & 0.180 & - & 0.198 & - & 0.276 & - & 0.291 & 0.792 & 0.360 & 0.910 & 0.364 \\
\hline B6-0.23g & - & 0.137 & - & 0.191 & - & 0.263 & - & 0.294 & 0.765 & 0.344 & 0.909 & 0.338 \\
\hline
\end{tabular}

Table 5 generalizes results displayed in Figure 15. Table 5 shows maximum absolute accelerations in top floors of prototype buildings. Like in Table 4, “-” refer to collapse.

Figures from Table 5 show that many accelerations are extremely high, thus explaining important number of cladding failures observed in Lorca. Moreover, non-structural elements were not adequately fixed to structure, as commonly observed in Spain. Table 5 provides following major remarks:

- Wall density. Accelerations of buildings without walls are 1.5 to 2.5 times smaller. This difference can be explained because response spectra ordinates (Figure 8.a) are lower for fundamental periods of buildings without walls (Table 1).

- NS / EW components. Regardless of building direction, accelerations under strong component are higher.

- Design PGA. Seismic design has no significant influence in response acceleration.

- Number of stories. In most cases, accelerations are clearly higher in 3-story buildings. Only exceptions correspond to buildings with high wall density. These tendencies can be explained by relation between fundamental periods (Table 1) and response spectra (Figure 8).

\subsection{Damage distribution}

Damage distribution patterns allow deeper insights on performance of analyzed buildings. Figure 16 and Figure 17 display examples of collapsed and not collapsed buildings, respectively.

Figure 16 refers to collapse mechanisms of buildings without walls B3-0.0g (Figure 9.d) and B60.0g (Figure 12.d) in wide beams $(x)$ direction under EW component. Figure 16 represents location and condition of each plastic hinge. Points " $\bigcirc$ ” correspond to onset of damage, either steel yielding or concrete cracking, points "๑" refer to formation of plastic hinge (yielding moment) and points “*”, indicate hinge failure (zero moment). Figure 16 shows also Park \& Ang damage index [Park, Ang 1985] of each story and of whole building. Figure 16 shows that most hinges commence and develop in columns, indicating a brittle "weak column-strong beam" collapse mechanism. Comparison between both buildings shows that in B6-0.0g, damage is more concentrated in lower levels. 


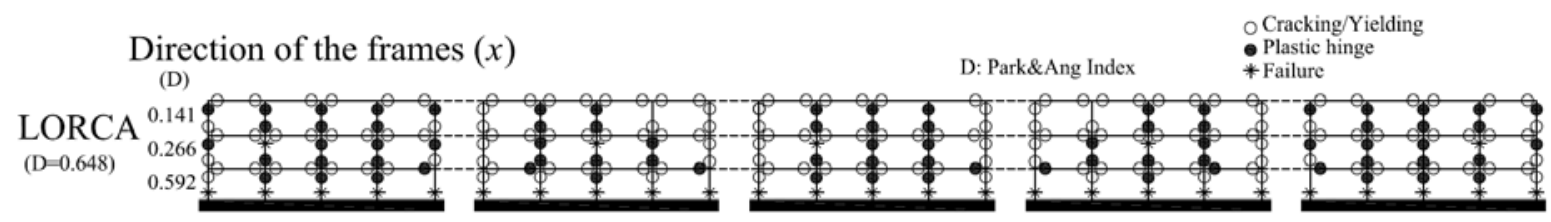

(a) Building B3-0.0g without walls. Wide beams direction $(x)$

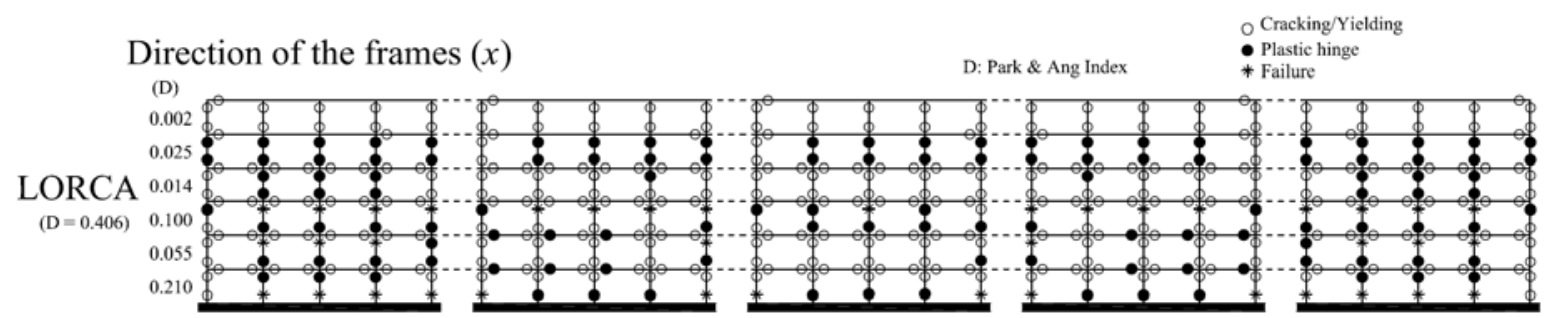

(b) Building B6-0.0g without walls. Wide beams direction $(x)$

Figure 16. Damage in non code-compliant prototype buildings that collapsed. EW component

Figure 17 refers to building B6-0.23g with high wall density (Figure 11). Damage distribution displayed in Figure 17 corresponds to final situation. Plots from Figure 17 show that, similarly to Figure 16, most of hinges appear in columns. 


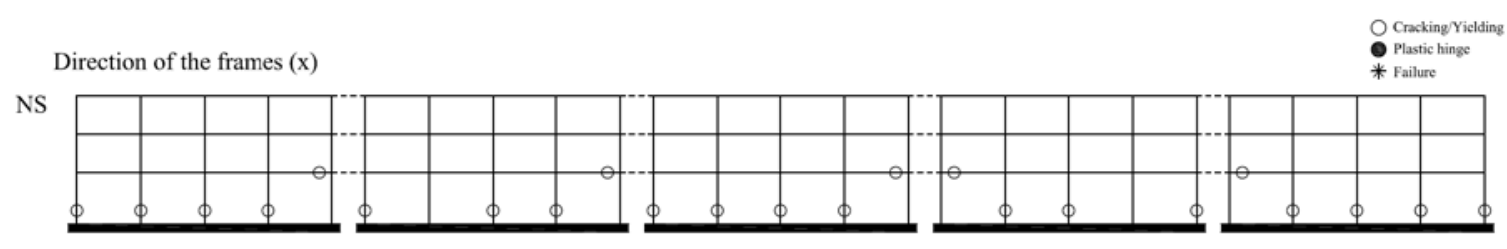

(a) NS component. Wide beams direction $(x)$

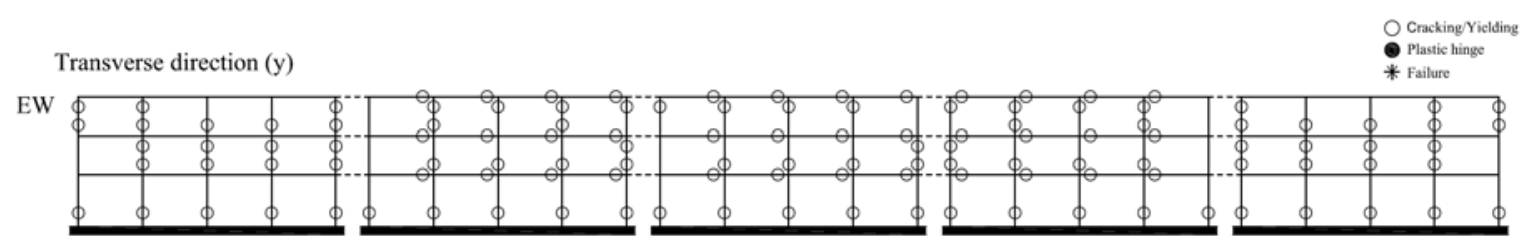

(b) EW component. Transverse direction $(y)$

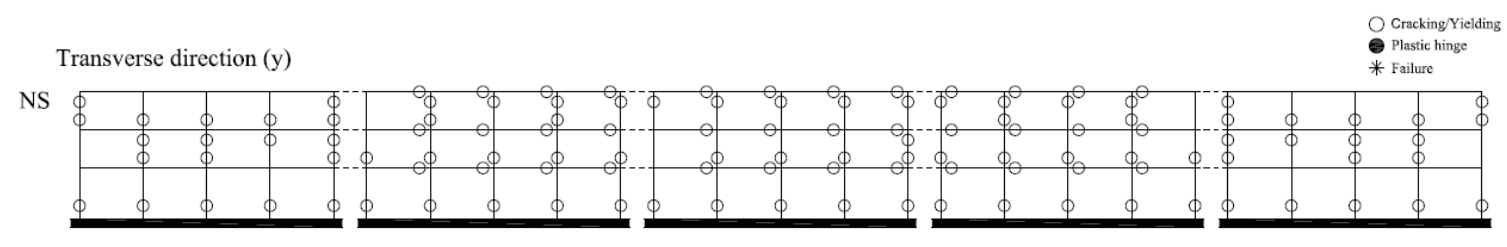

(c) NS component. Transverse direction (y)

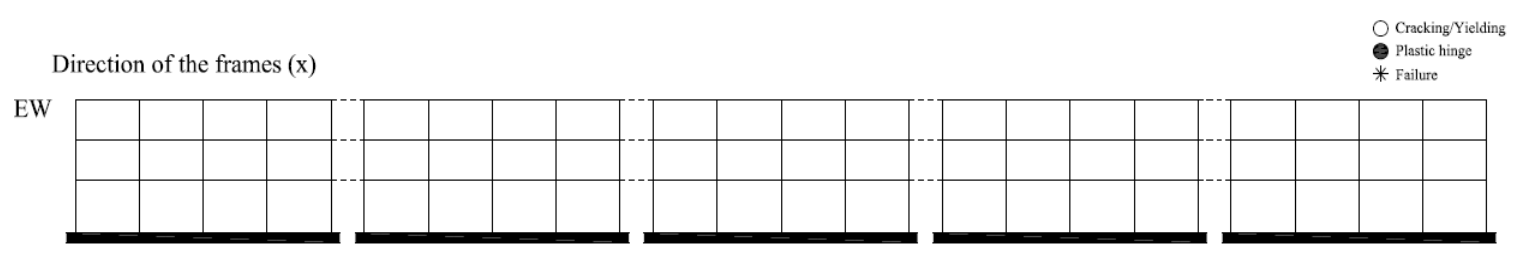

(d) EW component. Wide beams direction $(x)$

Figure 17. Damage in building B3-0.23g with high wall density

These observations will be used in further stages of research to propose tailored retrofit strategies.

\subsection{Energy balances}

Energy balance equation can provide relevant information on damage. That equation states that input energy is decomposed into damping, kinetic, and spring energy. Damping energy is dissipated through ordinary mechanisms, i.e. without additional damage. Spring energy accounts for sum of elastic potential and damaging energy; latter is energy that causes supplementary damage. Noticeably, once structural motion finishes, kinetic energy vanishes and, in structures whose response is mainly in nonlinear range, potential energy is negligible compared to plastic strain energy. Figure 18 displays time histories of energy components of buildings B3-0.23g (Figure 18.a) and B6-0.12g (Figure 18.b), both without walls, under EW component; such cases correspond to Figure 11.d and Figure 13.b, respectively. Figure 18 confirms that buildings suffer only moderate damage, since most input energy is dissipated by damping, and only approximately one sixth is absorbed and dissipated by spring. 


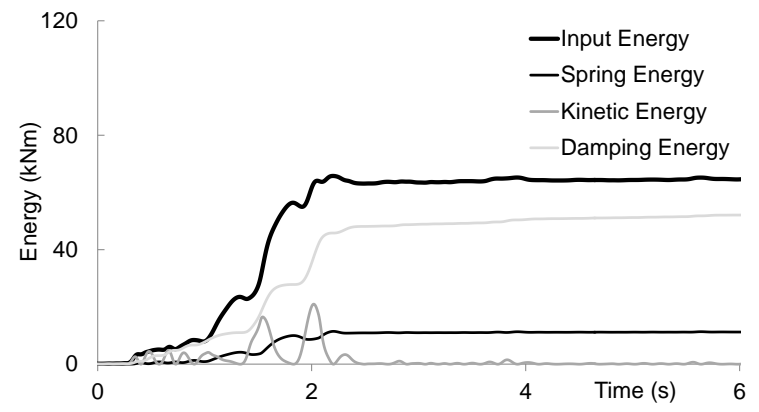

(a) Building B3-0.23g without walls. Wide beams direction $(x)$

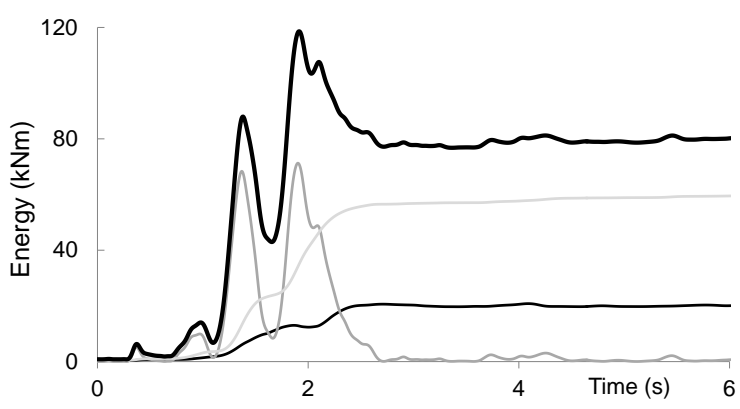

(b) Building B6-0.12g without walls. Transverse direction $(y)$

Figure 18. Time histories of energy. EW component.

For the sake of higher reliability, input energy in Figure 18 is compared with spectral ordinates in Figure 8.b. Input energy $E_{\mathrm{I}}$ is linked to equivalent velocity $V_{\mathrm{E}}$ by $E_{\mathrm{I}}=1 / 2 \mathrm{~m} V_{\mathrm{E}}^{2}$ where $m$ is building mass [Akiyama 1985]. Table 1 shows that, for building B3-0.23g, weight is $12005 \mathrm{kN}$ and fundamental period is $0.24 \mathrm{~s}$; for building B6-0.12g, such values are $26542 \mathrm{kN}$ and $1.1 \mathrm{~s}$. After these periods, $E_{\mathrm{I}}$ is obtained from spectrum in Figure 8.b:

$$
\begin{array}{ll}
\text { B3-0.23g / No walls / EW / } x \text { direction } & E_{\mathrm{I}}=\frac{1}{2} m V_{\mathrm{E}}^{2}=\frac{1}{2} 1200.5 \times 0.24^{2}=35 \mathrm{kNm} \\
\text { B6-0.12g / No walls / EW / } y \text { direction } & E_{\mathrm{I}}=\frac{1}{2} m V_{\mathrm{E}}^{2}=\frac{1}{2} 26542 \times 0.23^{2}=70 \mathrm{kNm}
\end{array}
$$

For building B6-0.12g, this result fits reasonably well with final input energy in Figure 18.b. Conversely, for building B3-0.23g, comparison with Figure 18.a shows higher discrepancy. This disagreement is due to consideration of initial (elastic) fundamental period to derive spectral ordinate $V_{\mathrm{E}}$ in Figure 8.b. When building undergoes plastic deformations, fundamental period $T_{\mathrm{F}}$ elongates and input energy is governed by a longer effective period. As shown in Figure 8.b, in vicinity of fundamental period of building B3-0.23g, elongation of $T_{\mathrm{F}}$ yields much higher values of $V_{\mathrm{E}}$ and, therefore, of $E_{\mathrm{I}}$; in contrast, in vicinity of fundamental period of building B6-0.12g, shape of $V_{\mathrm{E}}$ spectrum is approximately flat and elongation of $T_{\mathrm{F}}$ changes only slightly $V_{\mathrm{E}}$.

\section{Sensitivity analysis of numerical results}

\subsection{Parameters of analysis}

As discussed in subsection 1, objective of this paper is to investigate survivability of widespread Spanish wide-beam buildings under Lorca earthquake. Therefore, a number of prototype buildings are selected to represent most common wide-beam buildings in Spain. However, parameters of actual buildings are not uniform; therefore, to derive sounder conclusions, it is necessary to investigate sensitivity to major parameters of buildings. Parameters are selected accounting for its potential influence on results and their ranges are established based on its variability in actual buildings. Parameters are grouped into: geometrical (subsection 7.2), structural (subsection 7.3), wall (subsection 7.4) and damping (subsection 7.5)

\subsection{Influence of geometrical parameters}


This subsection investigates influence of major geometrical parameters of prototype buildings in their response under Lorca input. Parameters are span-length and column size; their ranges are decided after survey in [Domínguez 2012].

Span-length. In most of wide-beam buildings in Spain, span-length ranges between $5 \mathrm{~m}$ and slightly bigger values. Therefore, $5 \mathrm{~m}$ and $5.5 \mathrm{~m}$ are taken. Figure 19 displays top floor displacement response of building B3-0.0g with span-length $5.5 \mathrm{~m}$. Comparison with Figure 9 (corresponding to same building with span-length $5 \mathrm{~m}$ ) shows that results are rather similar showing that span-length influence is only moderate. For instance, in Figure 9.d, maximum displacement of building B3-0.0g (with high wall density) in $x$ direction is $17.5 \mathrm{~mm}$ and in Figure 19.d such displacement is $13 \mathrm{~mm}$.

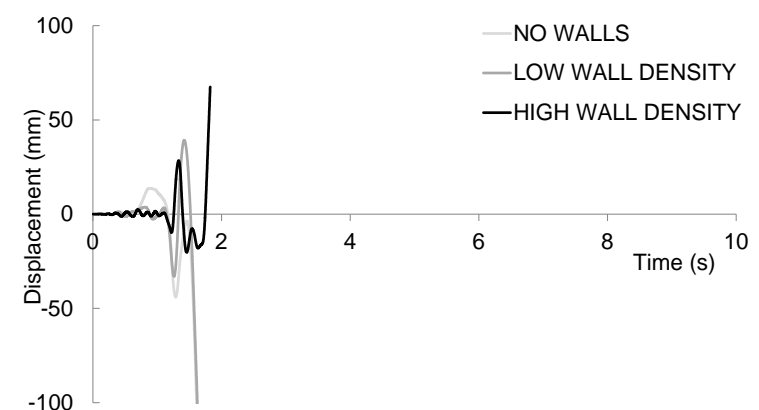

(a) NS component. Wide beams direction $(x)$

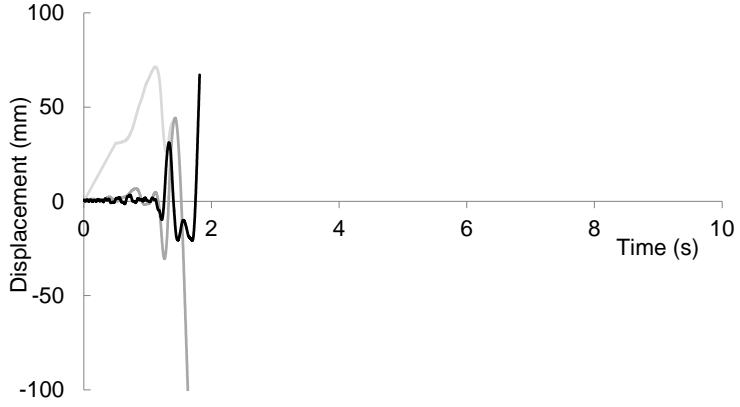

(c) NS component. Transverse direction (y)

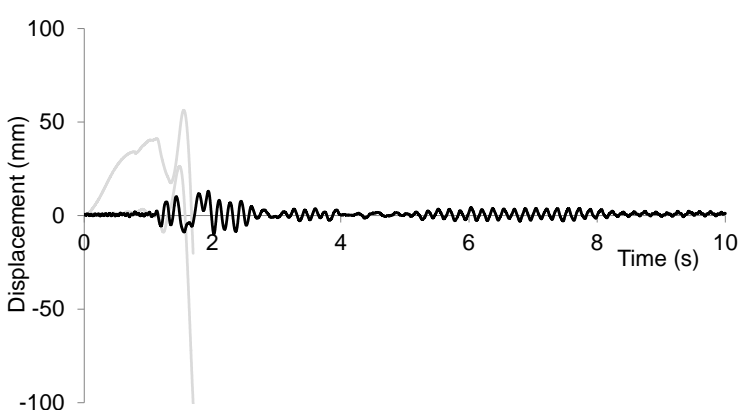

(b) EW component. Transverse direction (y)

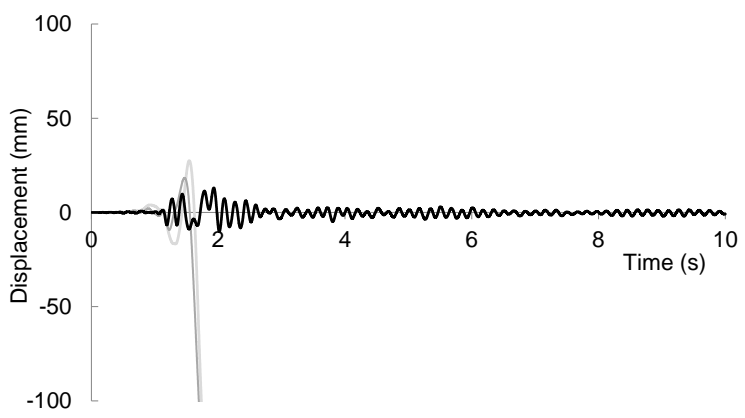

(d) EW component. Wide beams direction $(x)$

Figure 19. Top floor relative displacement response of non-code-compliant building B3-0.0g with spanlength $5.5 \mathrm{~m}$

Column section. In most wide-beam buildings in Spain, columns are either square or rectangular. Figure 20 displays top floor displacement response of building B6-0.0g with rectangular columns. Instead of square sections shown in Table 1, first and top floor columns are $60 \times 50$ and $40 \times 30$ $\mathrm{cm}^{2}$, respectively. Comparison with Figure 12 (corresponding to same building with square columns) shows that results are rather similar, since there is collapse in all cases. Therefore, columns size influence is only moderate. 


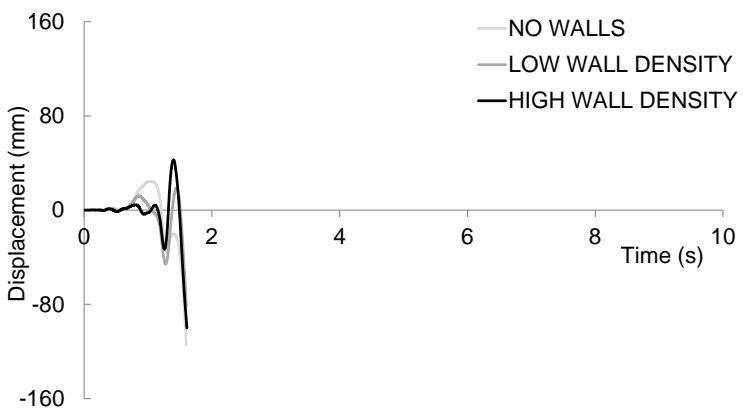

(a) NS component. Wide beams direction $(x)$

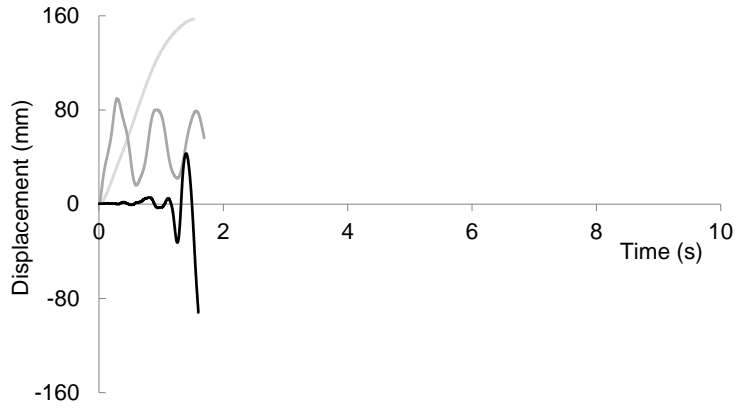

(c) NS component. Transverse direction $(y)$

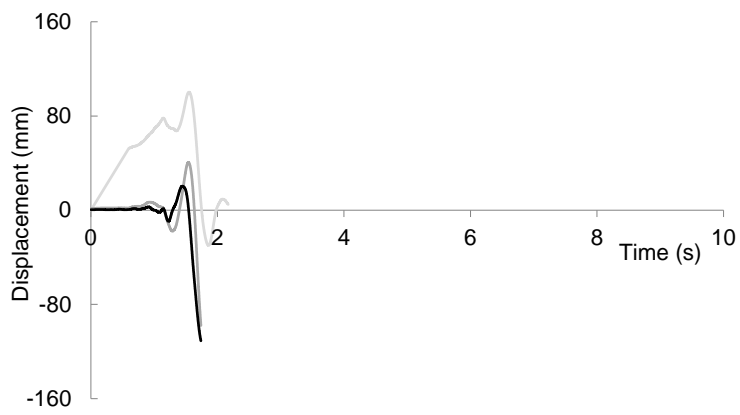

(b) EW component. Transverse direction (y)

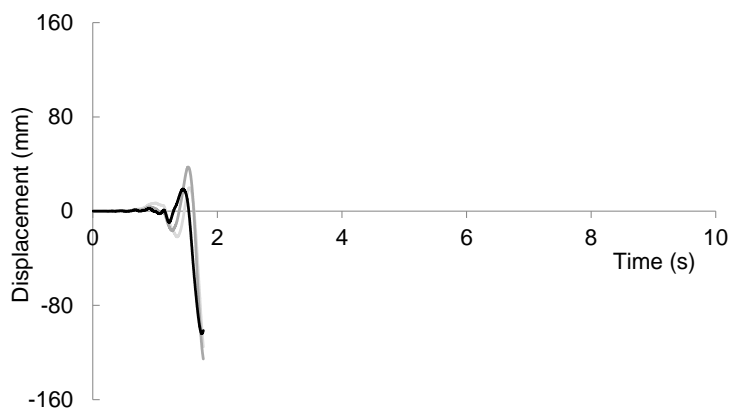

(d) EW component. Wide beams direction $(x)$

Figure 20. Top floor relative displacement response of non-code-compliant building B6-0.0g with rectangular columns

These results show that major geometrical parameters of prototype buildings do not affect significantly their response under Lorca input. Reference [Domínguez 2012] contains more results supporting this statement.

\subsection{Influence of structural parameters}

This subsection discusses influence of major structural parameters. Parameters are concrete and steel strength, and coefficients characterizing hysteretic behavior of plastic hinges. Regarding plastic hinges, its behavior is characterized by parameters HBD (strength degradation) and HS (pinching); not any of them has shown relevant influence. Representative results regarding influence of concrete and steel strength are presented and discussed next.

Concrete. Concrete is mainly characterized by compressive strength $f_{\mathrm{ck}}$. As discussed in subsection 2.3 , it is assumed that $f_{\mathrm{ck}}=17.5 \mathrm{MPa}$ for non code-compliant buildings (B3-0.0g and B6-0.0g) and $f_{\mathrm{ck}}=25 \mathrm{MPa}$ for code-compliant buildings (B3-0.12g, B3-0.23g, B6-0.12g and B6-0.23g). Conversely, given that current Spanish regulations [EHE 2008] state that minimum concrete strength is $25 \mathrm{MPa}$, it is assumed in this subsection for all buildings. Moreover, $f_{\mathrm{ck}}$ is characteristic value, while mean one $\left(f_{\mathrm{cm}}\right)$ would represent more realistically actual behavior of buildings. Therefore, $f_{\mathrm{cm}}$ is used instead of $f_{\mathrm{ck}}$ is in this subsection. Regarding that, European regulations [EN 1992 2003] indicate that $f_{\mathrm{cm}}=f_{\mathrm{ck}}+8 \mathrm{MPa}$. Furthermore, in existing buildings, concrete strength is significantly higher than $f_{\mathrm{cm}}$, since it corresponds to 28 days age; assuming Class $\mathrm{N}$ cement [EN 1992 2003], increment is approximately 30\%. Therefore, $f_{\mathrm{cm}}=(25+8) 1.30=43 \mathrm{MPa}$. Given that walls contribution is relevant and would conceal influence of concrete strength, only buildings without walls are considered herein. Regarding code-compliant buildings, Figure 21 displays top floor relative displacement response of buildings B3-0.23g and B6-0.12g without walls under EW component of Lorca input. Figure 21.a refers to building B3-0.23g in longitudinal direction ( $x$, 
Figure 11.d) and Figure 21.a represents building B6-0.12g in transverse direction (y, Figure 13.b). Concrete strength ranges between $25 \mathrm{MPa}$ (as in Figure 13.b) and $43 \mathrm{MPa}$. Plots from Figure 21 show that concrete strength affects significantly responses, both in peak values (Figure 21.a) and in permanent displacements (Figure 21.b).

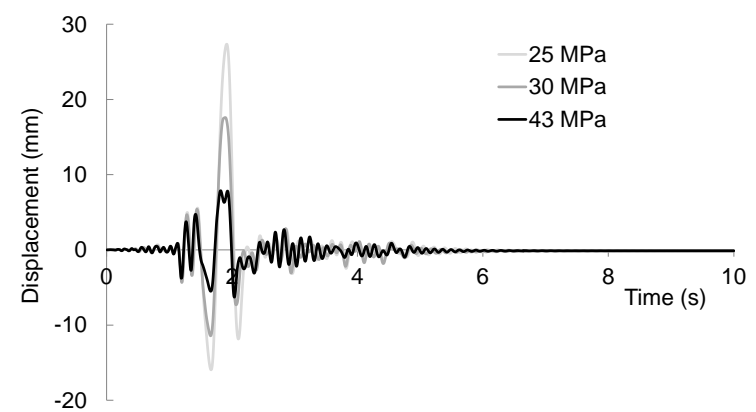

(a) Building B3-0.23g. Wide beams direction $(x)$

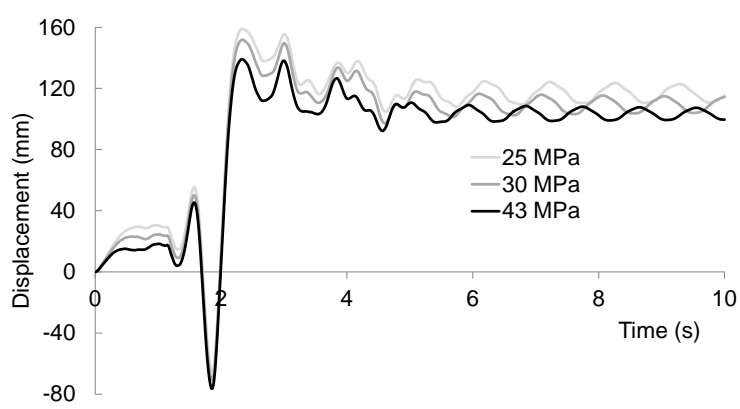

(b) Building B6-0.12g. Transverse direction $(y)$

Figure 21. Influence of concrete strength in top floor relative displacement response of code-compliant buildings B3-0.23g and B6-0.12g without walls. EW component

Regarding non code-compliant buildings without walls, if $f_{\mathrm{cm}}=43 \mathrm{MPa}$, only in two cases there is no collapse: buildings B3-0.0g and B6-0.0g in $x$ direction under EW component of Lorca record. Figure 9.d and Figure 12.d show that those cases with $f_{\mathrm{ck}}=17.5 \mathrm{MPa}$ collapse. However, these results lack of practical interest, since in the other direction ( $y$ direction under NS component), there is collapse in any case.

Steel. Steel is mainly characterized by yield point $f_{\mathrm{yk}}$. Several experimental studies [Otani et al. 2003; Benavent-Climent et al. 2015] highlighted relevant influence of strain rate. Following recommendations contained in these investigations, $12.5 \%$ increment of $f_{\mathrm{yk}}$ is considered in this subsection. As discussed in subsection $2.3, f_{\mathrm{yk}}=410 \mathrm{MPa}$ is assumed for non code-compliant buildings (B3-0.0g and B6-0.0g) and $f_{\mathrm{yk}}=500$ MPa for code-compliant buildings (B3-0.12g, B3$0.23 \mathrm{~g}, \mathrm{~B} 6-0.12 \mathrm{~g}$ and B6-0.23g). Conversely, following common current practices, $f_{\mathrm{yk}}=500 \mathrm{MPa}$ is adopted in this subsection for all buildings; as well, concrete strength is $43 \mathrm{MPa}$. Given that walls contribution is relevant and would mask influence of steel strength, only buildings without walls are studied herein. Regarding code-compliant buildings, Figure 22 displays top floor relative displacement response of buildings B3-0.23g and B6-0.12g without walls under EW component of Lorca input. Figure 22.a refers to building B3-0.23g in longitudinal direction ( $x$, Figure 21.a) and Figure 22.a represents building B6-0.12g in transverse direction ( $y$, Figure 21.b). Plots from Figure 22 show that steel strength influences response less intensively than concrete strength (Figure 21). This difference is mainly due to smallest range of variation and brittle sectional behavior of wide beams, with concrete failure preceding steel yielding.

Regarding non code-compliant buildings without walls, if $f_{\mathrm{yk}}=562.5 \mathrm{MPa}$, only in two cases there is no collapse: buildings B3-0.0g and B6-0.0g in $y$ direction under EW component of Lorca record. Figure 9.b and Figure 12.b show that those cases with $f_{\mathrm{yk}}=410 \mathrm{MPa}$ collapse. However, these results lack of practical interest since in the other direction ( $x$ direction under NS component), there is collapse in any case. 


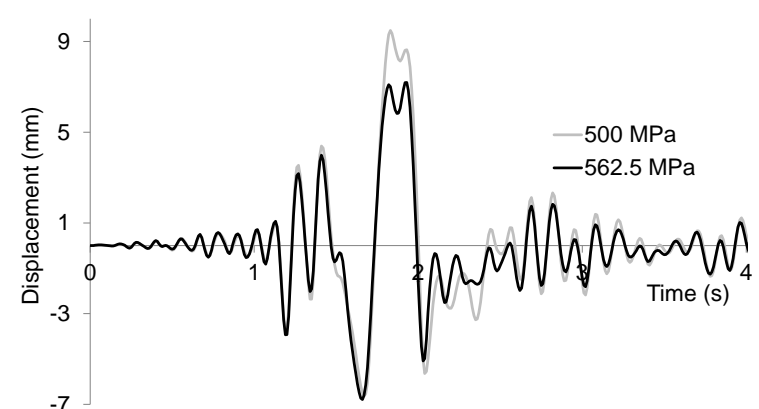

(a) Building B3-0.23g. Wide beams direction $(x)$

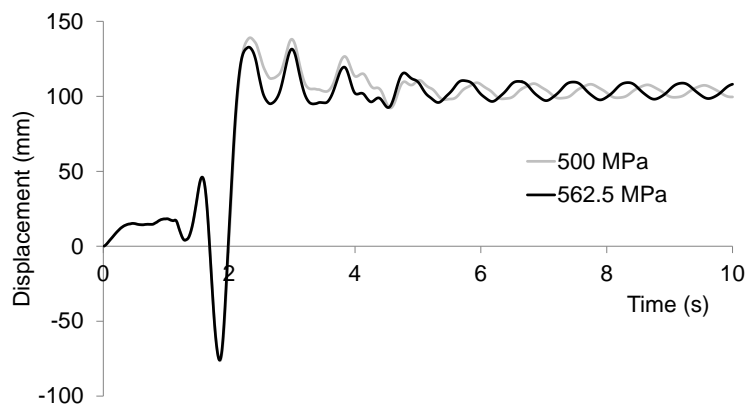

(b) Building B6-0.12g. Transverse direction $(y)$

Figure 22. Influence of steel strength in top floor relative displacement response of code-compliant buildings B3-0.23g and B6-0.12g without walls and $f_{\mathrm{cm}}=43 \mathrm{MPa}$. EW component

Results from this subsection show significant influence of major structural parameters, mainly concrete strength. Nevertheless, major statements from subsection 6.1 (mainly Table 4) hold.

\subsection{Influence of wall parameters}

Walls effect is considered through their initial stiffness (EAIW), strength (VYIW) and ductility (MU). Among these parameters, only VYIW and MU have shown relevant influence; representative results are presented and discussed next. Ranges of these parameters are wide, since control of nonstructural elements is commonly loose.

Strength. Figure 23 displays top floor relative displacement response of building B3-0.23g in wide beams direction $(x)$ subjected to NS component of Lorca input. In Figure 23, high and low wall densities, and VYIW $=252 \mathrm{kN}$ and VYIW $=452 \mathrm{kN}$ are combined. Comparison with Figure 11.a (showing results for VYIW = $352 \mathrm{kN}$ ), shows that wall strength influence is relevant, thus confirming leading role played by walls both in low and high wall density buildings.

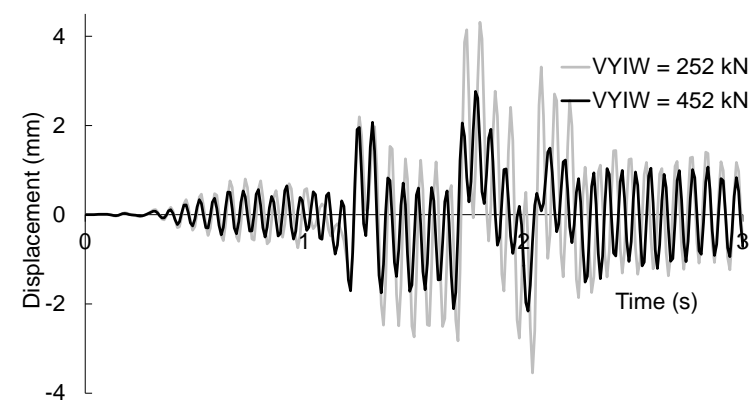

(a) High wall density

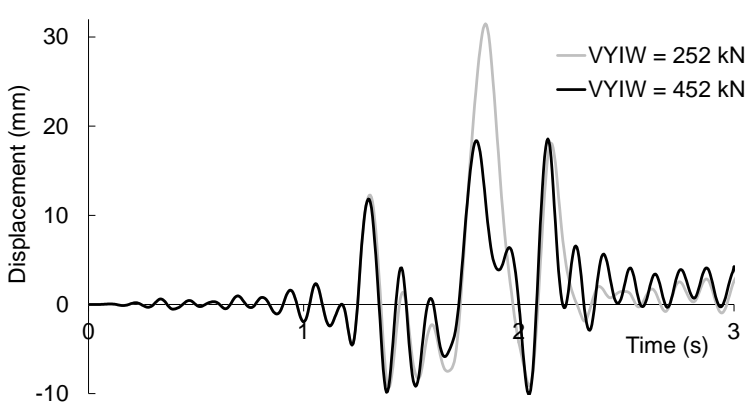

(b) Low wall density

Figure 23. Influence of wall strength in top floor relative displacement response of code-compliant building B3-0.23g. EAIW = $56 \mathrm{kN} / \mathrm{mm}$. MU = 15. NS component. Wide beams direction $(x)$

Ductility. As discussed in subsection 3.3, reference [Pujol et al. 2008] shows that $\mathrm{MU}=15$ provides better fit for ductile infill walls. In this study, low ductility walls with $\mathrm{MU}=2$ are also contemplated. Figure 24 displays comparisons among top floor time-history responses of codecompliant building B3-0.23g for $\mathrm{MU}=15$ and $\mathrm{MU}=2$. Responses correspond to NS component in wide beams direction. Figure 24.a shows that, for high wall density, response is insensitive to MU. 
Conversely, for low wall density, Figure 24.b shows some sensitivity to MU. This distinct behavior can be explained by absence of damage in Figure 24.a (Park \& Ang index is 0.0032).

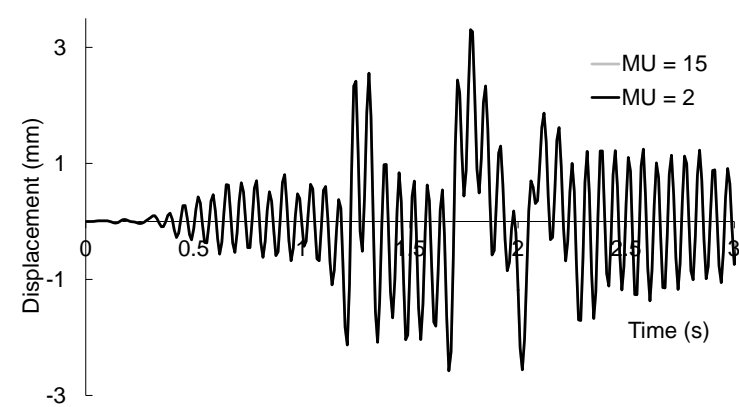

(a) High wall density

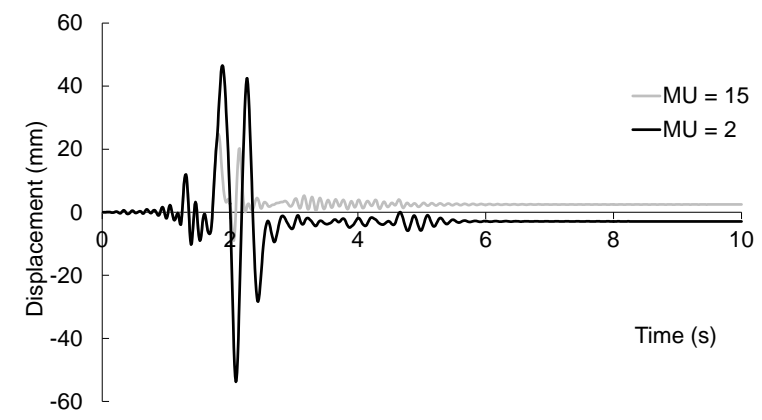

(b) Low wall density

Figure 24. Influence of wall ductility in top floor relative displacement response of code-compliant building B3-0.23g. EAIW $=56 \mathrm{kN} / \mathrm{mm}$. VYIW $=352 \mathrm{kN}$. NS component. Wide beams direction $(x)$

Results from this subsection show moderate influence of major wall structural parameters. In any case, major statements from subsection 6.1 (mainly Table 4) hold.

\subsection{Influence of damping}

In actual buildings, damping ratio can commonly exhibit only minor fluctuations. Moreover, recent studies [Martinelli, Filippou 2009; Benavent-Climent et al. 2013] have shown that near collapse behavior can be better reproduced using small damping factors, frequently near $1 \%$. Thus, this subsection presents a study regarding damping influence. Figure 25 displays top floor displacements of building B3-0.23g with damping factor ranging between 1 and 6\%; results correspond to wide beams direction $(x)$ and NS component. Plots from Figure 25 show a regular and expectable behavior, with non-neglectable sensitivity. Regarding small variations of damping factors, comparison between Figure 25.c and Figure 25.d shows only moderate influence. Regarding consideration of small damping factors, Figure 25. a shows that such assumption leads to big amplitude and permanent displacements. Given that this issue is still open, no final remarks can be stated.

\section{Conclusions}

This work presents a numerical study on dynamic response to Lorca earthquake (11-05-2011) of 3 and 6-story wide-beam prototype buildings. Given the low lateral resistance of main frame, cooperation of masonry infill walls is accounted for. Those buildings are designed for low, moderate and medium seismicity regions of Spain. Buildings in low seismicity region are designed without any seismic consideration. Obtained results show that:

- Buildings without walls. No building is expected to survive Lorca Earthquake. Common weaknesses that are presumable in wide-beam buildings contribute to this highly unsatisfactory seismic performance, combined with low concrete strength. In most cases, failure corresponds to brittle weak column-strong beam collapse mechanisms.

- Buildings with low wall density. 3-story buildings without seismic provisions collapse. 3-story buildings with seismic provisions resist Lorca input with moderate damage in columns and beams. All 6-story buildings collapse. 
- Buildings with high wall density. Buildings without seismic provisions collapse. Buildings with seismic provisions resist with moderate damage in columns and beams.

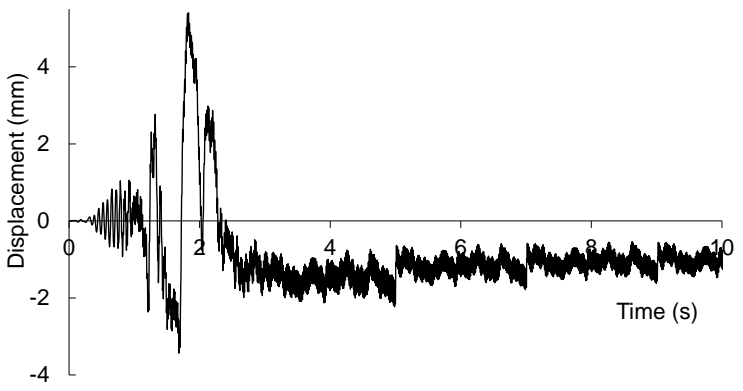

(a) Damping factor $1 \%$

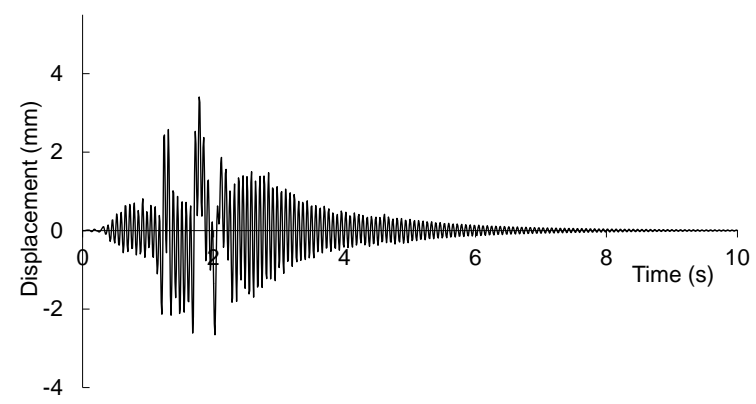

(c) Damping factor $4 \%$

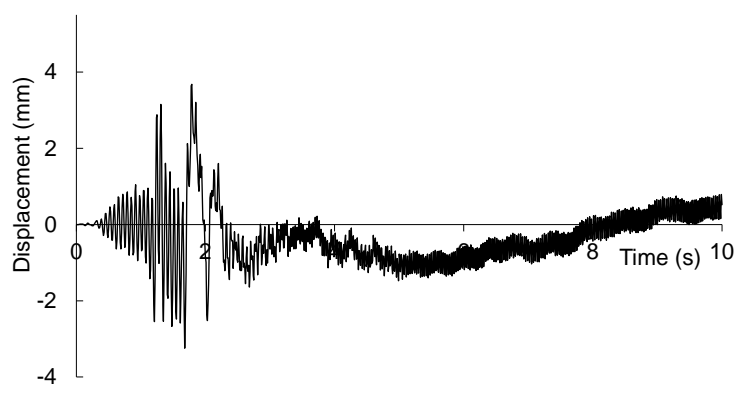

(b) Damping factor $2 \%$

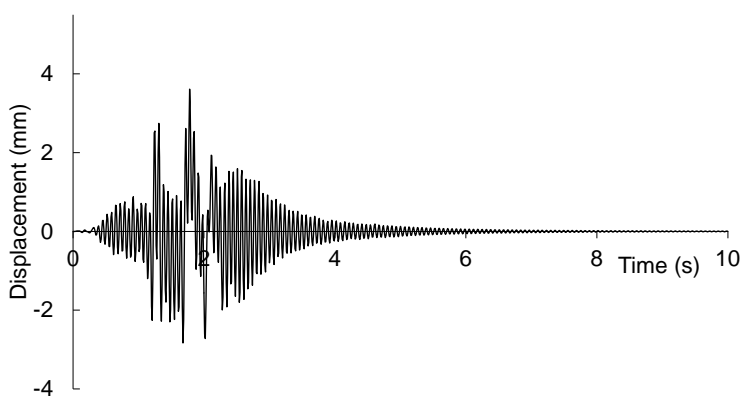

(d) Damping factor 6\%

Figure 25. Influence of damping in top floor relative displacement response of code-compliant building B3$0.23 g$ with high wall density. NS component. Wide beams direction $(x)$

Absolute response accelerations are determined; infill walls increase maximum accelerations 1.5 to 2.5 times. High obtained values explain important non-structural damage observed during Lorca earthquake; debris fall caused all fatalities.

Reliability of these conclusions is confirmed by a sensitivity analysis with respect to major geometrical, structural and damping parameters. This analysis has shown that influence of geometrical and damping parameters is only moderate, while structural parameters, mainly concrete and wall strength, exhibit higher influence. Nevertheless, major statements from basic study hold. A research aiming to propose retrofit strategies is currently in progress.

Acknowledgements: This paper is financed by Spanish Government under projects CGL2011-2362 and BIA2011-26816 and from European Union (Feder); this support is gratefully acknowledged.

\section{References}

ACI 318-08 (2008), Building Code Requirements for Structural Concrete and Commentary, American Concrete Institute. Akiyama H (1985), Earthquake-resistant limit-state design for buildings, University of Tokyo Press, Tokyo.

Arias A, (1970), A measure of earthquake intensity, Seismic Design for Nuclear Power Plants, MIT Press.

Baber TT, Noori MN (1985), Random Vibration of Degrading Pinching Systems, Journal of Engineering Mechanics, 111(8). 1010-1026.

Baker JW (2007), Quantitative Classification of Near-Fault Ground Motions Using Wavelet Analysis, Bulletin of the Seismological Society of America, 97(5):1486-1501. http://dx.doi.org/10.1785/0120060255.

Benavent-Climent A, Pujades LG, López-Almansa F (2002), Design energy input spectra for moderate seismicity regions, Earthquake Engineering \& Structural Dynamics, 31:1151-1172. 
Benavent-Climent A (2007), Seismic behavior of RC beam-column connections under dynamic loading, Journal of Earthquake Engineering, 11:493-511.

Benavent-Climent A, Cahís X, Vico JM (2009a), Interior wide beam-column connections in existing RC frames subjected to lateral earthquake loading, Bulletin of Earthquake Engineering, 8(2) 401-420. DOI: 10.1007/s10518-009-9144-3.

Benavent-Climent A, Cahís X, Zahran R (2009b), Exterior wide beam column connections in existing RC frames subjected to lateral earthquake loads, Engineering Structures, 31 141-1424.

Benavent-Climent A, Zahran R (2010), An energy-based procedure for the assessment of seismic capacity of existing frames: application to RC wide beam systems in Spain, Soil Dynamics and Earthquake Engineering, 30(5):354-367.

Benavent-Climent A, Donaire-Ávila J, Escobedo A, Oliver-Sáiz E, Ramírez-Márquez AL, Feriche M (2012), Damage assessment on building structures subjected to the recent near-fault earthquake in Lorca (Spain), $15^{\text {th }}$ WCEE, Lisbon.

Benavent-Climent A, Escobedo A, Donaire-Ávila J, Oliver-Sáiz E, Ramírez-Márquez AL (2013), Assessment of expected damage on buildings subjected to Lorca earthquake through an energy-based seismic index method and nonlinear dynamic response analyses, Bulletin of Earthquake Engineering, 12(5) 2049-2073. DOI 10.1007/s10518-013-9513-9.

Benavent-Climent A, Oliver-Saiz E, Donaire-Avila J (2015), New connection between reinforced concrete building frames and concentric braces: shaking table tests, Engineering Structures, in press. DOI: 10.1016/j.engstruct.2015.03.023.

Bentz E, Collins MP (2000), Response-2000, V.1.0.5. Toronto University. Toronto, Ontario, Canada.

Cabañas L, Carreño E, Izquierdo A, Martínez JM, Capote R, Martínez J, Benito B, Gaspar J, Rivas, A, García J, Pérez R, Rodríguez MA, Murphy P (2011), Informe del sismo de Lorca del 11 de mayo de 2011, IGN, UCM, UPM, IGME, AEIS, available at http://www.ign.es/ign/resources/sismologia/Lorca.pdf (in Spanish).

Cardone D, (2007), Nonlinear Static Methods vs. Experimental Shaking Table Test Results, Journal of Earthquake Engineering, 11:847-875. DOI: 10.1080/13632460601173938.

De Luca F, Verderame GM, Gómez-Martínez F, Pérez-García A (2013), The structural role played by masonry infills on RC building performances after the 2011 Lorca, Spain, earthquake, Bulletin of Earthquake Engineering, 12(5) 19992026. DOI. 10.1007/s10518-013-9500-1.

Dickinson BW, Gavin HP (2011), Parametric statistical generalization of uniform-hazard earthquake ground motions, Journal of Structural Engineering, 137(3):410-422.

Domínguez D (2012), Evaluación de la capacidad sismorresistente de edificios con vigas planas situados en zonas de España de sismicidad baja a moderada, Doctoral Thesis, Technical University of Catalonia.

Domínguez D, López Almansa F, Benavent Climent A (2014), Comportamiento, para el terremoto de Lorca de 11-052011, de edificios de vigas planas proyectados sin tener en cuenta la acción sísmica, Informes de la Construcción, 66(553), e008. DOI: http://dx.doi.org/10.3989/ic.12.092.

EH-80 (1980), Instrucción para el proyecto y ejecución de obras de hormigón en masa o armado, Ministerio de Fomento.

EHE (2008), Instrucción de Hormigón Estructural, Ministerio de Fomento.

EN 1992 (Eurocode 2). (2003), Design of Concrete Structures, European Committee for Normalization.

EN 1996 (Eurocode 6). (2005), Design of Masonry Structures, European Committee for Normalization.

EN 1998 (Eurocode 8). (2005), Design of Structures for Earthquake Resistance, European Committee for Normalization.

ESD European strong-motion database. <http://www.isesd.hi.is/ESD_local/frameset.htm> [accessed 02.14].

Feriche M, Equipo de Trabajo del IAGPDS (2011), Efectos del Terremoto de Lorca en las edificaciones, Available at http://www.ugr.es/ iag/lorca/Efecto_edificaciones.pdf.

Feriche M, Vidal F, Alguacil G, Navarro M, Aranda C (2012), Vulnerabilidad y daño en el terremoto de Lorca de 2011, $7^{\mathrm{a}}$ Asamblea hispano-portuguesa de Geodesia y Geofísica. San Sebastián.

Gentry RG, Wight JK (1994), Wide beam-column connections under earthquake-type loading. Earthquake Spectra, 10(4). 675-703.

Gómez-Martínez F, Pérez-García A, De Luca F, Verderame GM (2015), Comportamiento de los edificios de HA con tabiquería durante el sismo de Lorca de 2011: aplicación del método FAST, Informes de la Construcción, 67(537). doi:10.3989/ic.12.110.

Goula X, Figueras S, Irizarry J, Macau A, Barbat A, Lantada N, Carreño ML, Valcárcel J, Combescure D, Belvaux M, Monfort D, Bremond S, Verrhiest G, Camares C, Bairrao R (2011), Rapport de la mission AFPS du séisme de Lorca, available at http://www.afps-seisme.org/index.php/fre/Seismes-majeurs/Seisme-a-Lorca (in Spanish).

Hermanns L, Fraile A, Alarcón E, Álvarez R (2013), Performance of buildings with masonry infill walls during the 2011 Lorca earthquake, Bulletin of Earthquake Engineering, 12(5) 1977-1997. DOI 10.1007/s10518-013-9499-3.

IGME (2011), Informe geológico preliminar del terremoto de Lorca del 11 de mayo del año 2011, $5.1 M_{\mathrm{w}}$, Instituto Geológico y Minero de España.

IGME (2015), Terremoto en Ossa de Montiel (Albacete) de magnitud 5,2, Instituto Geológico y Minero de España. Downloadable at http://info.igme.es/eventos/ (last accessed, April 2015).

IGN (2011), Serie terremoto NE Lorca (Murcia) 11/05/2011, Instituto Geográfico Nacional.

Kempton JJ, Stewart JP (2006), Prediction Equations for Significant Duration of Earthquake Ground Motions Considering Site and Near-Source Effects, Earthquake Spectra, 22:4 985-1013.

Kunnath SK, Reinhorn AM (2010), IDARC 2D Version 7.0. Program for the Inelastic Damage Analysis of Reinforced Concrete Structure, State University of New York at Buffalo. 
López Almansa F, Domínguez D, Benavent Climent A (2013), Seismic performance of RC buildings with wide beams, Engineering Structures, 46 687-702.

López-Comino JA, Mancilla FdL, Morales J, Stich D (2012), Rupture directivity of the 2011, Mw 5.2211 Lorca earthquake (Spain), Geophysical Research Letters, 39 L03301.

Manfredi G (2001), Evaluation of seismic energy demand, Earthquake Engineering \& Structural Dynamics, 30:1 485499.

Martinelli P, Filippou FC (2009), Simulation of the shaking table test of a seven-story shear wall building, Earthquake Engineering \& Structural Dynamics, 38:587-607.

Martínez JL, Martín JA, León J (2001), Comportamiento mecánico de la obra de fábrica. Monografía sobre el análisis estructural de construcciones históricas de fábrica, Universidad Politécnica de Madrid.

Martínez-Díaz JJ, Béjar-Pizarro M, Álvarez-Gómez JA, Mancilla FdL, Stich D, Herrera G., Morales J. (2012), Tectonic and seismic implications of an intersegment rupture. The damaging May 11th $2011 \mathrm{Mw} 5.2$ Lorca, Spain, earthquake, Tectonophysics, 546-547 28-37.

Masi A (2003), Seismic Vulnerability Assessment of Gravity Load Designed R/C Frames, Bulletin of Earthquake Engineering, 1:371-395.

Mehrabi AB, Shing PB, Schuller MP, Noland JL (1994), Performance of masonry-infilled RC frames under in-plane lateral loads, Report CD/SR-94/6. University of Colorado at Boulder.

Mostafaei H, Kabeyasawa T (2004), Effect of Infill Masonry Walls on the Seismic Response of Reinforced Concrete Buildings, Bulletin of the Earthquake Research Institute, University of Tokyo. 79:133-156.

Navarro M, García-Jerez A, Alcalá FJ, Vidal F, Enomoto T (2014), Local site effect microzonation of Lorca town (SE Spain), Bulletin of Earthquake Engineering, 12(5):1933-1959. doi:10.1007/s10518-013-9491-y.

NCSE-02 (2002), Norma de Construcción Sismorresistente, Ministerio de Fomento.

Newmark NM (1959), A method of computation for structural dynamics, Journal of Engineering Mechanics, ASCE, 85(EM3), 67-94.

Otani S, Kaneko T, Shiohara H (2003), Strain Rate Effect on Performance of Reinforced Concrete Members, Proceedings of fib symposium, Concrete Structures in Seismic Regions, Athens.

Park YJ, Ang AH (1985), Mechanistic seismic damage model for reinforced concrete, Journal of Structural Engineering, ASCE. 111:4, 722-739.

Paulay T, Priestley MJN (1992), Seismic Design of Reinforced Concrete and Masonry Buildings. Wiley.

Popov EP, Cohen E, Koso-Thomas K, Kasai K (1992), Behavior of interior narrow and wide beams, ACI Structural Journal 89(6):607-616.

Pujol S, Benavent-Climent A, Rodríguez ME, Smith-Pardo JP (2008), Masonry infill walls: an effective alternative for seismic strengthening of low-rise reinforced concrete building structures, 14WCEE, Beijing, China.

Quintero-Febres CG, Wight JK (2001), Experimental study of reinforced concrete interior wide beam-column connections subjected to lateral loading. ACI Structural Journal, 98(4):572-582.

Reinhorn AM, Roh H, Sivaselvan M, Kunnath SK, Vallés RE, Madan A, Li C, Lobo R, Park YJ (2009), IDARC 2D Version 7.0. Program for the Inelastic Damage Analysis of Structures, MCEER Technical Report MCEER-09- 006. State University of New York at Buffalo.

Ricci P, de Risi MT, Verderame GM, Manfredi G (2013), Influence of infill distribution and design typology on seismic performance of low- and mid-rise RC buildings, Bulletin of Earthquake Engineering, 11:5 1585-1616.

Salgado-Gálvez MA, Carreño ML, Barbat AH, Cardona OD (2015), Probabilistic seismic risk assessment of Lorca through scenario simulations (in Spanish), RIMNI, in press. doi:10.1016/j.rimni.2014.12.001.

Seismosoft (2013), SeismoStruct v6.5 - A computer program for static and dynamic nonlinear analysis of framed structures, available from http://www.seismosoft.com.

Siah WL, Stehle JS, Mendis P, Goldsworthy H (2003), Interior wide beam connections subjected to lateral earthquake loading. Engineering Structures, 25:281-291.

Sivaselvan MV, Reinhorn AM (1999), Hysteretic models for cyclic behavior of deteriorating inelastic structures. Rep. No. NCEER-99-0018, National Center for Earthquake Engineering Research, State University of New York at Buffalo.

Sugano S (1968), Study on inelastic stiffness of reinforced concrete structures, Research reports of the Annual Meeting of the Architectural Institute of Japan Kanto Branch. Tokyo, Japan, 3 25-32.

Trifunac MD, Brady AG (1975), A study on the duration of strong earthquake ground motion, Bulletin of the Seismological Society of America, 65:3, 581-626.

Vidal F, Navarro M, Aranda C, Enomoto T (2013), Changes in dynamic characteristics of Lorca RC buildings from preand post-earthquake ambient vibration data, Bulletin of Earthquake Engineering, 12(5) 2095-2110. DOI 10.1007/s10518-013-9489-5.

Vissers RLM, Meijninger BML (2011), The 11 May 2011 earthquake at Lorca (SE Spain) viewed in a structural-tectonic context, Solid Earth, 2:199-204.

Zhai C, Chang Z, Li S, Chen Z, Xie L (2013), Quantitative Identification of Near-Fault Pulse-Like Ground Motions Based on Energy, Bulletin of the Seismological Society of America, 103(5):2591-2603. http://dx.doi.org/10.1785/0120120320. 